\title{
Eigenvalue Analysis of a Network Connected to a Wind Turbine Implemented with a Doubly-Fed Induction Generator (DFIG)
}

\author{
M. Jazaeri ${ }^{1}$, A.A. Samadi ${ }^{* 2}$, H.R. Najafi ${ }^{3}$, N. Noroozi-Varcheshme ${ }^{4}$ \\ ${ }^{1,2}$ Faculty of Electrical and Computer Engineering, Department of Electric Power Engineering, \\ University of Semnan, Semnan, Iran \\ *a.a.samadi@gmail.com \\ ${ }^{3}$ Faculty of Electrical Engineering, Department of Electric Power Engineering, University of Birjand, \\ Birjand, Iran \\ ${ }^{4}$ Department of Electrical Engineering , Minoodasht Branch, Islamic Azad University, \\ Minoodasht, Iran
}

\begin{abstract}
Recently, the growing integration of wind energy into power networks has had a significant impact on power system stability. Amongst types of large capacity wind turbines (WTs), doubly-fed induction generator (DFIG) wind turbines represent an important percentage. This paper attemps to study the impact of DFIG wind turbines on the power system stability and dynamics by modeling all components of a case study system (CSS). Modal analysis is used for the study of the dynamic stability of the CSS. The system dynamics are studied by examining the eigenvalues of the matrix system of the case study and the impact of all parameters of the CSS are studied in normal, subsynchronous and super-synchronous modes. The results of the eigenvalue analysis are verified by using dynamic simulation software. The results show that each of the electrical and mechanical parameters of the CSS affect specific eigenvalues.
\end{abstract}

Keywords: wind turbine, doubly-fed induction generator (DFIG), dynamic modeling, eigenvalue analysis.

\section{Introduction}

In the last few years, the increasing wind power penetration in electric power systems and its effect on the dynamic stability of the power system, specifically on weak networks, have become important issues of concern. Among the various types of wind turbines, variable-speed DFIG-based wind turbines have attracted particular attention because of their many advantages over those based on fixed-speed generators; some of the advantages are increased efficiency, reduced cost of power electronic components, reduced mechanical stress and independent control capabilities for active and reactive powers [1, 2, 3].

The simulation of the dynamic behavior of DFIG wind turbines has been intensely investigated using dynamic simulations software [4,5]. The significance of these investigations is that they are based on time-domain simulations by power system analysis tools to show the impact of wind turbines on power system dynamics $[6,7]$.

The accurate modeling of all components of these WTs and the study of their effects on the power

system are important. The dynamic modeling of DFIG wind turbines has been studied in several papers $[8,9,10]$. In these documents, dynamic models of DFIG systems are presented in different order. In some articles the use of dynamic models, eigenvalue analysis, and artificial intelligence techniques such as PSO has set the control system parameters of power electronic converters $[11,12.13]$.

In previous studies, the impact of DFIG systems on power system dynamic stability has analytically been investigated. These studies have been conducted mainly on variations of wind speed at subsynchronous and super-synchronous modes. In these studies, the influence of the transmission line parameters, load system, and dynamics of controllers have not been investigated; in addition, the strength of networks connected to WTs $[14,15]$ has not been mentioned in related papers. Thereby, in this paper, by accurately modeling all components of a variable-speed DFIG wind turbine in a CSS connected to a network, the impact of 


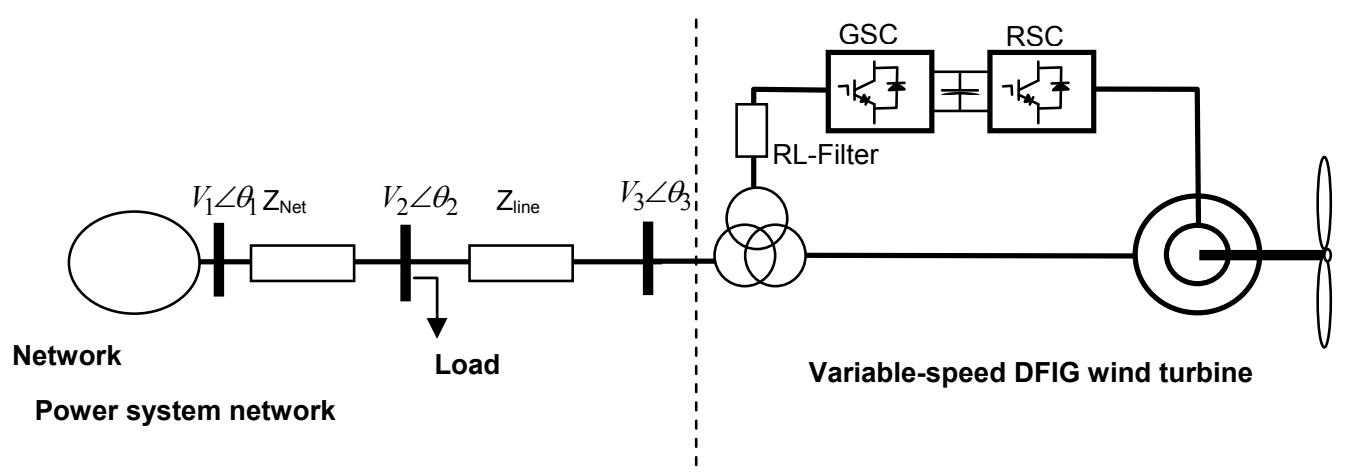

Figure 1. Case study system.

different parameters of network and WT on the dynamic stability of the CSS has been studied.

In the modeling of the CSS, a seventh-order DFIG wind turbine, the dynamics of the pitch controller system and the rotor and stator converters are considered for a precise study, a short line model is used and the branch shunt is neglected. Constant impedance is used for the load model. The network is modeled with a power supply and equivalent impedance that represents the strength of network.

For the dynamic stability analysis, the deferentialalgebraic equations (DAE) of the CSS are linearized around an operating point. The operating point is obtained by a simultaneous solution of DAE for a steady state condition. The eigenvalues of the CSS resulted from a system matrix. The trajectory behavior and the sensitivity of eigenvalues are investigated for various parameters of network and WT in normal, subsynchronous and super-synchronous modes. The results of the eigenvalue analysis are verified by dynamic simulation of the CSS in Matlab simulation tools.

\section{Case study system (CSS)}

The CSS illustrated in Figure 1 comprises a variable-speed DFIG wind turbine connected to the network by a transmission line. The load bus is located between the bus and the wind turbine; hence, the complete model of the CSS includes the following components: DFIG model, power electronic converter model, transformer, transmission line, load, drive train and pitch controller model.

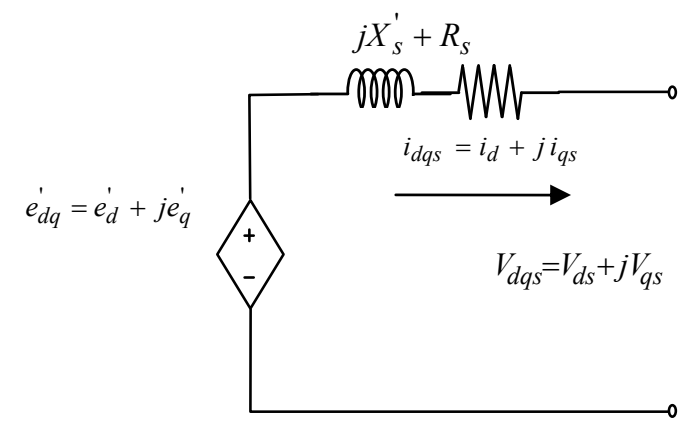

Figure 2. Dynamic model of DFIG.

\subsection{DFIG model}

In dynamic stability studies, the model of machines is usually represented as a voltage source behind transient impedance $[16,17]$; therefore equivalent circuit of the DFIG is shown in Figure 2. This equivalent circuit is the result of a written voltage and the current equations of the rotor and the stator of the DFIG in dq frame to another form; hence, the DFIG model can be written by the following equations:

$$
\begin{aligned}
& \frac{d i_{d s}}{d t}=-\left[\frac{\omega_{s}}{X_{s}^{\prime}}\left(R_{s}+\frac{X_{s}-X_{s}^{\prime}}{\omega_{s}^{\prime} T_{o}^{\prime}}\right)\right] i_{d s}+\omega_{s} i_{q s}+ \\
& {\left[\frac{\omega_{r}}{X_{s}^{\prime}}\right] e_{d}^{\prime}-\left[\frac{1}{X_{s}^{\prime} T_{o}^{\prime}}\right] e_{q}^{\prime}-\left[\frac{\omega_{s}}{X_{s}^{\prime}}\right] V_{d s}+\left[\frac{\omega_{s}}{X_{s}^{\prime}} \frac{L_{m}}{L_{r r}}\right] V_{d r}}
\end{aligned}
$$




$$
\begin{aligned}
& \frac{d i_{q s}}{d t}=-\omega_{s} i_{d s}-\left[\frac{\omega_{s}}{X_{s}^{\prime}}\left(R_{s}+\frac{X_{s}-X_{s}^{\prime}}{\omega_{s} T_{s}^{\prime}}\right)\right] i_{q s}+ \\
& {\left[\frac{\omega_{s}}{X_{s}^{\prime} T_{o}^{\prime}}\right] e_{d}^{\prime}+\left[\frac{\omega_{r}}{X_{s}^{\prime}}\right] e_{q}^{\prime}-\left[\frac{\omega_{s}}{X_{s}^{\prime}}\right] V_{q s}+\left[\frac{\omega_{s}}{X_{s}^{\prime}} \frac{L_{m}}{L_{r}}\right] V_{q r}}
\end{aligned}
$$

$$
\begin{aligned}
\frac{d e_{d}^{\prime}}{d t}=\left[\frac{X_{s}-X_{s}^{\prime}}{T_{o}^{\prime}}\right] i_{q s}-\left[\frac{1}{T_{o}^{\prime}}\right] e_{d}^{\prime}+\left[\left(\omega_{s}-\omega_{r}\right)\right] e_{q}^{\prime}-\left[\omega_{s} \frac{L_{m}}{L_{r r}}\right] V_{q r} & V_{1}=\frac{K_{r}}{1+T_{r} s} V_{2} \\
\text { (3) } & I_{f}=\frac{V_{f}-V_{s}}{Z_{f}}
\end{aligned}
$$$$
\frac{d e_{q}^{\prime}}{d t}=-\left[\left(\frac{X_{s}-X_{s}^{\prime}}{T_{o}^{\prime}}\right)\right] i_{d s}-\left[\left(\omega_{s}-\omega_{r}\right)\right] e_{d}^{\prime}-\left[\frac{1}{T_{o}^{\prime}}\right] e_{q}^{\prime}+\left[\omega_{s} \frac{L_{m}}{L_{r}}\right] V_{d r}
$$

$$
i_{d r}=-\left(\frac{1}{\omega_{s} L_{m}}\right) e_{q}^{\prime}-\left(\frac{L_{m}}{L_{r r}}\right) i_{d s}
$$$$
i_{q r}=-\left(\frac{1}{L_{m} \omega_{s}}\right) e_{d}^{\cdot}-\left(\frac{L_{m}}{L_{r r}}\right) i_{q s}
$$$$
\psi_{d s}=-\left(1 / \omega_{s}\right) e_{q}^{\prime}+\left(X_{s}^{\prime} / \omega_{s}\right) i_{d s}
$$$$
\psi_{q s}=-\left(1 / \omega_{s}\right) e_{d}^{\prime}+\left(X_{s}^{\prime} / \omega_{s}\right) i_{q s}
$$$$
e_{d}^{\prime}=\left(\frac{L_{m}}{L_{r r}}\right) \omega_{s} \psi_{q r}
$$$$
e_{q}^{\prime}=-\left(\frac{L_{m}}{L_{r r}}\right) \omega_{s} \psi_{d r}
$$$$
X_{s}^{\prime}=\omega_{s}\left(L_{s s} L_{r r}-L_{m}^{2}\right) / L_{r r}
$$$$
T_{o}^{\prime}=\omega_{s} L_{r r} / R_{r}
$$

where $\psi$ is the flux, $\mathrm{L}$ is the inductance, $R$ is the resistance, $X^{\prime}$ is the transient reactance, $X$ is the reactance, $T_{o}^{\prime}$ is the transient time constant, $e^{\prime}$ is the voltage behind the transient impedance, the subscripts of ' $r$ ','s' are related to the rotor and the stator, respectively, and the subscripts of ' $d$ ', ' $q$ ' are related to the quarter and the orthogonal of the coordinate axes, respectively.

\subsection{Power electronic converter model}

In a DFIG wind turbine, the power electronic converter (PEC) is located between the rotor winding of the DFIG and the network; PECs are usually PWM voltage source converters separated by a DC-link as shown in Figure 3.

In dynamic studies, PECs, which are usually modeled as simple gains or else as first-order systems, are presented. In Equation $13, \mathrm{~K}_{\mathrm{r}}$ is the gain of the converter, expressed as the ratio of output voltage magnitude $V_{1}$ to input voltage $V_{2}$, and $T_{r}$ is the time constant of the converter, which is usually very small and can be neglected [16]. In Figure $3, Z_{f}$ is the impedance of the filter between the converter and the network. The effect of the filter on system performance is expressed in Equation 14. The current of filter $I_{f}$ and the impact of its parameters are applied in equations related to the dynamics of the networkside converter controller.

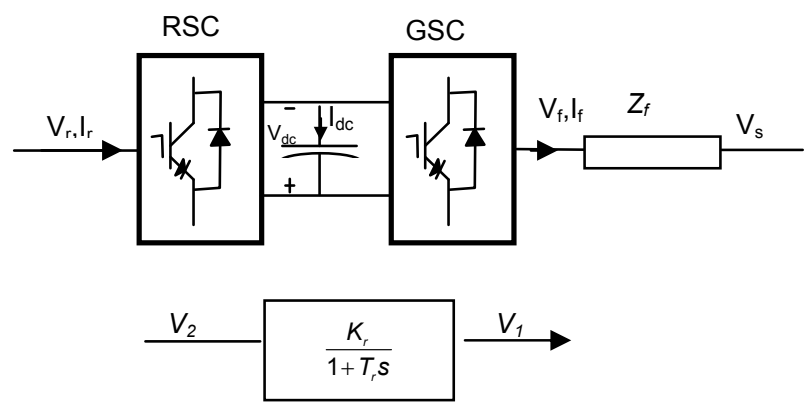

Figure 3. Power electronic converter and dynamic model.

\subsubsection{Dynamics of the rotor-side converter} controller

Through the vector control method, the active and reactive power are controlled independently via quarter and orthogonal of coordinate axes [18]. The control block diagrams of the rotor-side converter are illustrated in Figure 4. By introducing 


\section{Eigenvalue Analysis of a Network Connected to a Wind Turbine Implemented with a Doubly-Fed Induction Generator (DFIG), M. Jazaeri et al. / $791-811$}

intermediate variables $x_{1}, x_{2}, x_{3}$ and $x_{4}$, the following equations can be expressed [16]:

$$
\begin{gathered}
\frac{d X_{1}}{d t}=P_{r e f}-P_{s} \\
i_{q r}^{*}=K_{p 1}\left(P_{r e f}-P_{s}\right)+K_{i 1} X_{1} \\
\frac{d X_{2}}{d t}=i_{q r}^{*}-i_{q r} \\
\left.\left.V_{q r}^{*}=V_{q r}^{*}-\left(\omega_{s}-\omega_{r}\right)\left(i_{q r}^{*}-i_{q r}\right)+K_{i 2} X_{2} I_{d r}+L_{m} I_{d s}\right)\right\}-R_{r} I_{q r} \\
Q_{s}=v_{d s} i_{q s}-v_{q s} i_{d s} \\
\frac{d X_{3}}{d t}=Q_{r e t}-Q_{s}
\end{gathered}
$$

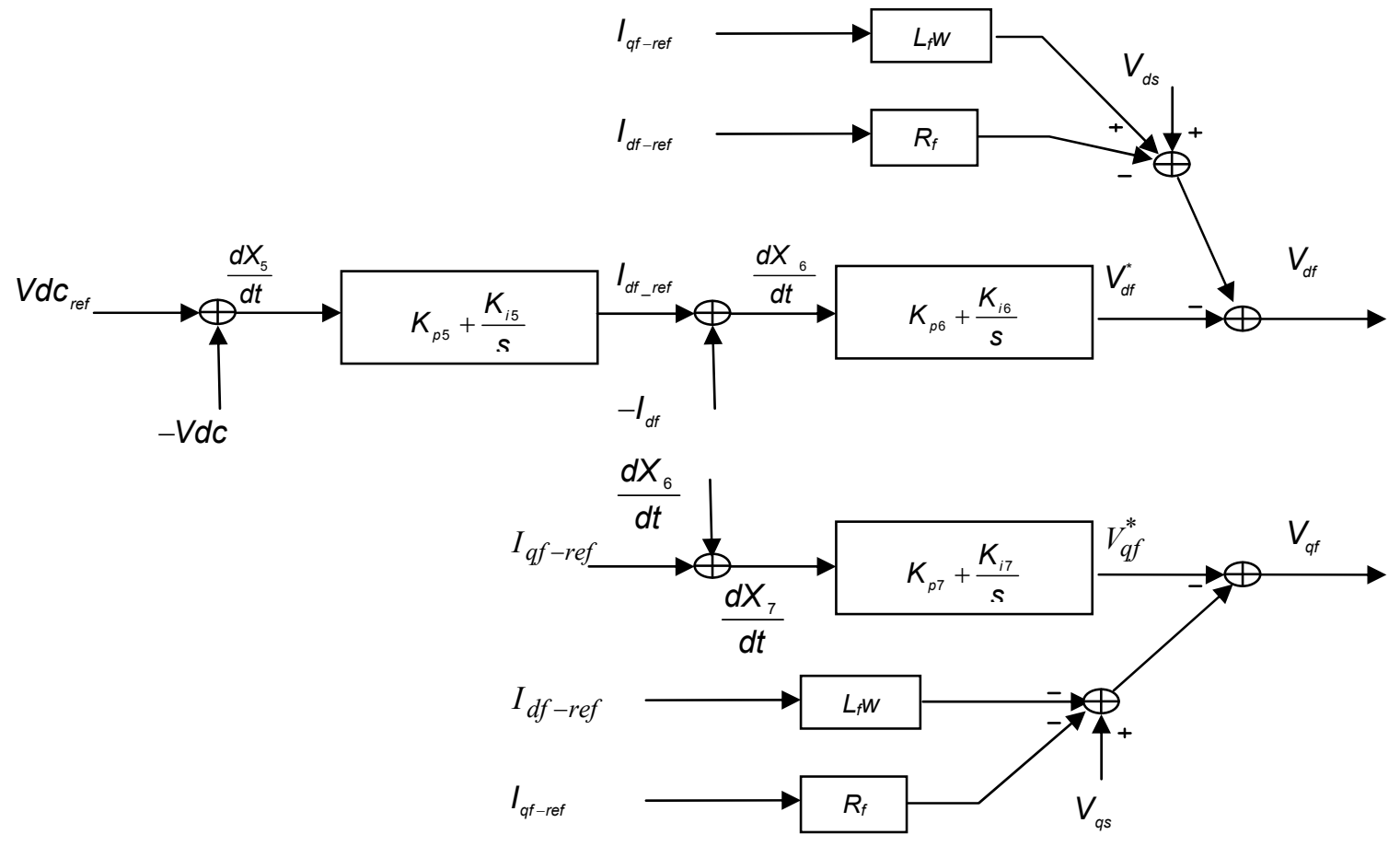

Figure 5. Control block diagrams of the grid-side converter. 
introducing intermediate variables $x_{5}, x_{6}$ and $x_{7}$, the following equations can be obtained [16]:

$$
\begin{gathered}
\frac{d X_{5}}{d t}=V_{d c}^{*}-V_{d c} \\
i_{d f}^{*}=K_{p 5}\left(V_{d c}^{*}-V_{d c}\right)+K_{i 5} X_{5} \\
\frac{d X_{6}}{d t}=i_{d f}^{*}-i_{d f} \\
V_{d f}=\left(\left(V_{d s}\right)-R_{f f} I_{d f}^{*}+\omega_{s} L_{f} I_{q f}^{*}\right)-V_{d f}^{*} \\
V_{d f}^{*}=K_{p 6}\left(i_{d f}^{*}-i_{d f}\right)+K_{i 6} X_{6} \\
Q_{f}=V_{d f} i_{q f}-V_{q g} i_{d g} \\
\frac{d X_{7}}{d t}=i_{q f}^{*}-i_{q f} \\
V_{q f}=\left(\left(V_{q s}\right)-R_{f} I_{q f}^{*}-\omega_{s} L_{f} I_{d f}^{*}\right)-V_{q f}^{*} \\
i_{q f}=\frac{V_{q f}-V_{q f}}{\sqrt{R_{f}^{2}+X_{f}^{2}}} \\
(32) \\
\left.V_{q f}^{*}-i_{q f}\right)+K_{i 7} X_{7}
\end{gathered}
$$

Where $V_{d c}$ is the DC-link voltage and "*" is used as reference value.Subscript " $f$ " is related to the filter elements.

\subsubsection{Dynamics of the DC-link capacitor}

The active power flow is balanced through the converters. Hence, the power balance equation for defining the dynamics of DC-link capacitor is the following [16]:

$$
\frac{d V_{d c}}{d t}=\frac{1}{c V_{d c}}\left\{\left(V_{d r} i_{d r}+v_{q r} i_{q r}\right)-\left(v_{d f} i_{d f}+v_{q f} i_{q f}\right)\right\}
$$

If the dynamics of the DC-link capacitor is neglected and $V_{d c}$ is constant then $\mathrm{dV}_{\mathrm{dc}} / \mathrm{dt}=0 . i_{f}$ is filter current achieved by Equation 14.

\subsection{Transformer model}

Using $\pi$ model of transformer is common in networks. Besides, in dynamic stability studies, the shunt branch is neglected and transformer model is usually presented by series impedance [19]. A simplified model of transformer is shown in Figure 6. In this figure $Z$ is total impedance of HV and LV sides of transformer in per unit.

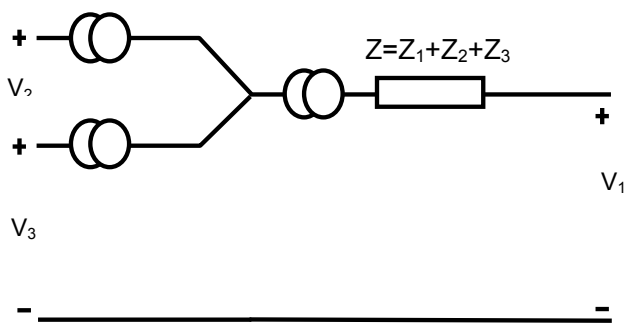

Figure 6. Model of transformer.

$$
Z_{1}=Z_{H}+Z_{L}^{\prime}
$$

\subsection{Drive train model}

Figure 7 shows the drive train model of the wind turbine. The drive train includes a turbine, gearbox, shafts and other mechanical components of the WT. The generator rotor shaft is connected to the turbine shaft flexibly via gearbox and coupling [15].

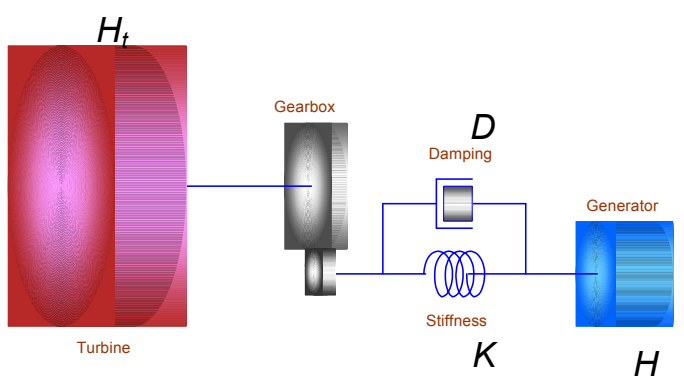

Figure 7. Drive train model of the wind turbine. 
The two-mass model is given by the following equations:

$$
\begin{gathered}
\frac{d \omega_{t}}{d t}=\frac{1}{2 H_{t}} T_{m}-\frac{K}{2 H_{t}} \theta_{t w}-\frac{D}{2 H_{t}} \omega_{t}+\frac{D}{2 H_{t}} \omega_{r} \\
\frac{d \omega_{r}}{d t}=\frac{K}{2 H_{g}} \theta_{t w}+\frac{D}{2 H_{g}} \omega_{t}-\frac{D}{2 H_{g}} \omega_{r}-\frac{T_{e}}{2 H_{g}} \\
\frac{d \theta_{t w}}{d t}=\omega_{t}-\omega_{r}
\end{gathered}
$$

Where $H_{t}$ and $H_{g}$ are the turbine and generator inertia, $\omega_{t}$ and $\omega_{r}$ are the turbine and DFIG rotor speed, and $\theta_{t w}$ is the shaft torsion angle, $K$ the shaft stiffness, and $D$ the damping coefficient, $T_{e}$ is the electromagnetic torque and $T_{m}$ is mechanical torque produced by wind turbine. $T_{e}$ and $T_{m}$ can be determined by:

$$
\begin{gathered}
T_{e}=\frac{P_{s}}{\omega_{s}}=\left(\frac{e_{q}^{\prime}}{\omega_{s}}\right) I_{q s}+\left(\frac{e_{d}^{\prime}}{\omega_{s}}\right) I_{d s} \\
T_{m}=0.5 \rho \pi R^{2} c_{p} V_{w}^{3} / \omega_{t} \\
\lambda-\frac{\omega_{t} R}{V_{w}}=0 \\
C_{p}(\lambda, \beta)=c_{1}\left(\frac{c_{2}}{\lambda_{i}}-c_{3} \beta-c_{4}\right) \cdot e^{\frac{-c 5}{\lambda i}}+c_{6} \lambda \\
\frac{1}{\lambda_{i}}=\frac{1}{\lambda+0.08 \beta}-\frac{0.035}{\beta^{3}+1}
\end{gathered}
$$

Where $V_{w}$ is wind speed, $C_{p}$ is the power coefficient, $\beta$ is the pitch angle, $R$ is the rotorblade radius, $\rho$ is the air density and, $\lambda$ is the tip speed ratio.

\subsubsection{Pitch controller model}

Pitch control is one of the controlling methods for power and speed control of turbine rotor. Almost all variable-speed wind turbines use pitch control (Figure 8). The dynamics of the pitch controller is given by [14]

$$
\frac{d \beta}{d t}=\frac{1}{T_{\text {pitch }}}\left(K_{\text {pitch }}\left(\omega_{r}-\omega_{r}^{*}\right)-\beta\right)
$$

Where $\mathrm{K}_{\text {pitch }}$ is the gain of the WT pitch controller, $\mathrm{T}_{\text {pitch }}$ is time constant of WT pitch controller.

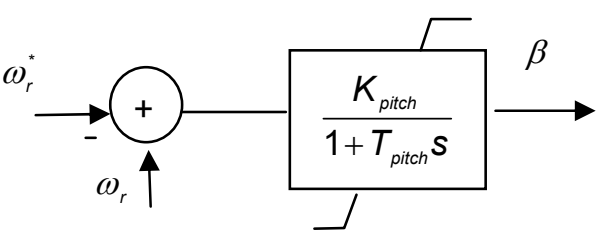

Figure 8. Pitch controller model.

\subsection{Load model}

In power system stability study, a common practice is to represent the composite load characteristics. The response of most composite loads to voltage and frequency changes is fast and the steady state of the response is reached very quickly. This is true at least for modest amplitude of voltage/frequency change [17]. Here load model is considered as constant impedance. In the load modeling by constant impedance, load power changes are proportional to the voltage squared. The equations related to the constant impedance load can be written as: [17]

$$
\begin{aligned}
& Z_{\text {Load }}=\frac{V_{i}{ }^{2}}{S^{*}}=\frac{V_{i}{ }^{2}}{P_{1}-j Q_{1}}, \\
& P_{1}=Z_{\text {Load }}{ }^{*} \cos \varphi, Q_{1}=Z_{\text {Load }}{ }^{*} \sin \varphi
\end{aligned}
$$

Where $Z_{\text {Load }}$ is impedance of load and $\varphi$ is the angle between voltage and current.

\subsection{Line model}

The fastest dynamics are those associated with the very fast wave phenomena that occur in transmission lines [20]. Therefore, in this study, 
steady-state model of line is considered. For steady-state model the interest variables are the voltages and currents at the line terminals, these parameters can be determined by [17]:

$$
\begin{aligned}
& {\left[\begin{array}{l}
V_{s} \\
I_{s}
\end{array}\right]=\left[\begin{array}{cc}
\cosh \gamma & Z_{c} \sinh \gamma \\
1 / Z_{c} \sinh \gamma & \cosh \gamma
\end{array}\right]\left[\begin{array}{c}
V_{R} \\
I_{R}
\end{array}\right]} \\
& Z_{c}=\sqrt{\frac{z}{y}} \gamma=\sqrt{z y}
\end{aligned}
$$

Where $I_{s}, I_{r}$ are currents and $V_{s}, V_{r}$ are voltages of line terminal, while Subscripts ' $s$ ' indicate the sending end of the line, ' $r$ ' stands for the receiving end. $Z$ and $Y$ are impedance and admittance of line.

\subsection{Network model}

In dynamic stability studies, network is usually represented as a source voltage behind network equivalent impedance for simplicity [18]. Network equivalent circuit is shown in Figure 9.

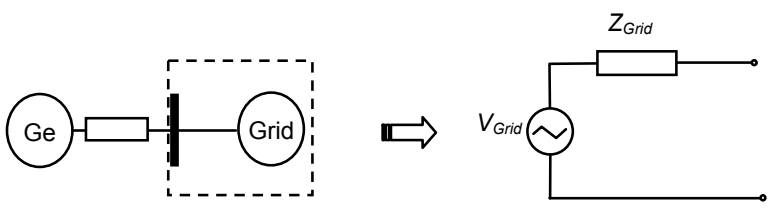

Figure 9. Network model

\section{Differential-algebraic model of the CSS}

To develop a power system dynamic simulation the equations used to model the different elements are collected together to form a set of differential equations that describes the system dynamics. A set of algebraic equations includes the algebraic equations of network and equations of the stator of the DFIG, as follows:

$$
\begin{aligned}
& x=f(x, y, u) \\
& 0=g(x, y)
\end{aligned}
$$

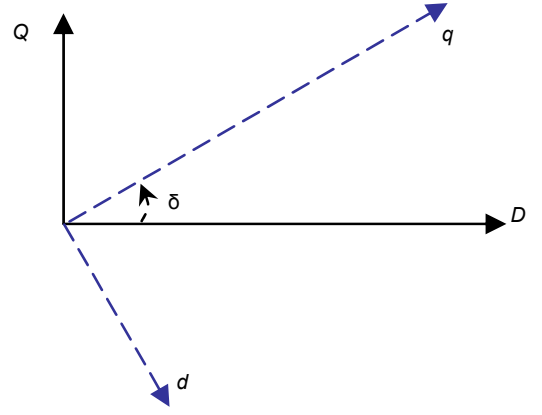

Figure 10. Reference frame conversion.

Each system model is expressed in its own d-q reference frame which rotates with its rotor. For the solution of interconnecting network equations, all voltages and currents must be expressed in a common reference. Usually a reference frame rotating at synchronous speed is used [17] (Figure 10). Thus, when writing the power equations of the grid connected DFIG, transformation from one frame to another should be applied appropriately $[17,16]$. The dq and DQ variables are related by:

$$
\begin{aligned}
& {\left[\begin{array}{l}
F_{d} \\
F_{q}
\end{array}\right]=\left[\begin{array}{cc}
\sin \delta & -\cos \delta \\
\cos \delta & \sin \delta
\end{array}\right]\left[\begin{array}{l}
F_{D} \\
F_{Q}
\end{array}\right],} \\
& {\left[\begin{array}{l}
F_{D} \\
F_{Q}
\end{array}\right]=\left[\begin{array}{cc}
\sin \delta & \cos \delta \\
-\cos \delta & \sin \delta
\end{array}\right]\left[\begin{array}{l}
F_{d} \\
F_{q}
\end{array}\right],} \\
& \frac{d \delta}{d t}=\omega_{r}-\omega_{s}
\end{aligned}
$$

\subsection{Algebraic equations of the stator of the DFIG}

Algebraic equations of the stator of the DFIG obtained directly from dynamic circuit equivalent of DFIG. By applying KVL law in Figure 2. The following equations can be written:

$$
\begin{aligned}
& e_{d}^{\prime}-V_{d s}-R_{s} i_{d s}+X_{s}^{\prime} i_{q s}=0 \\
& e_{q}^{\prime}-V_{q s}-R_{s} i_{q s}-X_{s}^{\prime} i_{d s}=0
\end{aligned}
$$

\subsection{Algebraic equations of the network}

Power flow equations on the load bus and the wind turbine bus organize the algebraic equations of the network. In Figure 1, the CSS is considered as 3 bus systems. The magnitude and angle of each 
bus is attributed to a parameter. Therefore, power flow equations on the buses are as follows: [16]

Bus 1:

$$
\begin{aligned}
& g_{24}(x, y)=\left|V_{1}\right|^{2} 1 /\left|Z_{12}\right| \cos \left(\alpha_{12}\right)- \\
& \left|V_{1}\right|\left|V_{2}\right| 1 /\left|Z_{12}\right| \cos \left(\theta_{1}-\theta_{2}+\alpha_{12}\right)-P_{1}=0 \\
& \left|V_{1}\right|^{2} 1 /\left|Z_{12}\right| \sin \left(\alpha_{12}\right)- \\
& \left|V_{1}\right|\left|V_{2}\right| 1 /\left|Z_{12}\right| \sin \left(\theta_{1}-\theta_{2}+\alpha_{12}\right)-Q_{1}=0
\end{aligned}
$$

Bus 2:

$$
\begin{aligned}
& g_{22}(x, y)=\left|V_{2}\right|^{2} 1 / Z_{12} \mid \cos \left(\alpha_{12}\right)- \\
& \left.\left|V_{3}\right| V_{2}|1 /| Z_{32}\left|\cos \left(\theta_{2}-\theta_{3}+\alpha_{32}\right)+\right| V_{2}\right|^{2} 1 / Z_{32} \mid \cos \left(\alpha_{32}\right) \\
& -\left|V_{1}\right|\left|V_{2}\right| 1 /\left|Z_{12}\right| \cos \left(\theta_{2}-\theta_{1}+\alpha_{12}\right)+\left|V_{2}\right|^{2} 1 /\left|Z_{L}\right| \cos \left(\alpha_{L}\right)=0
\end{aligned}
$$

$$
\begin{aligned}
& g_{23}(x, y)=\left|V_{2}\right|^{2} 1 /\left|Z_{12}\right| \sin \left(\alpha_{12}\right)- \\
& \left|V_{3}\right|\left|V_{2}\right| 1 /\left|Z_{32}\right| \sin \left(\theta_{2}-\theta_{3}+\alpha_{32}\right)+\left|V_{2}\right|^{2} 1 /\left|Z_{32}\right| \sin \left(\alpha_{32}\right) \\
& -\left|V_{1}\right|\left|V_{2}\right| 1 /\left|Z_{12}\right| \sin \left(\theta_{2}-\theta_{1}+\alpha_{12}\right)+\left|V_{2}\right|^{2} 1 /\left|Z_{L}\right| \sin \left(\alpha_{L}\right)=0
\end{aligned}
$$

\section{Bus 3:}

$$
\begin{aligned}
& g_{20}(x, y)=\left|V_{3}\right|^{2} 1 /\left|Z_{32}\right| \cos \left(\alpha_{32}\right)- \\
& \left|V_{3}\right|\left|E^{\prime}\right| 1 /\left|Z_{D F I G}\right| \cos \left(\theta_{3}-\delta_{e}+\alpha_{z D F I G}\right) \\
& +\left|V_{3}\right|^{2} 1 /\left|Z_{D F I G}\right| \cos \left(\alpha_{z D F I G}\right)- \\
& \left|V_{3}\right|\left|V_{2}\right| 1 /\left|Z_{32}\right| \cos \left(\theta_{3}-\theta_{2}+\alpha_{32}\right)=0, \\
& Z_{D F I G}=R_{s}+j X_{s}^{\prime} \\
& g_{21}(x, y)=\left|V_{3}\right|^{2} 1 /\left|Z_{32}\right| \sin \left(\alpha_{32}\right)- \\
& \left|V_{3}\right|\left|E^{\prime}\right| 1 /\left|Z_{D F I G}\right| \sin \left(\theta_{3}-\delta_{e}+\alpha_{z D F I G}\right) \\
& +\left|V_{3}\right|^{2} 1 /\left|Z_{D F I G}\right| \sin \left(\alpha_{z D F I G}\right)- \\
& \left|V_{3}\right|\left|V_{2}\right| 1 /\left|Z_{32}\right| \sin \left(\theta_{3}-\theta_{2}+\alpha_{32}\right)=0
\end{aligned}
$$

Hence, the complete DAE model of the CSS is as follows:

1- Deferential equations of the DFIG,((1) (4))

2- Deferential equations of the PEC controller and dynamics of the DC-link (15), (17), (21), (23), (24), (28), (33), and (32).

3- Deferential equations of the drive train system of the wind turbine (39), (40), and (41).

4- Deferential equation of the pitch controller system (47).

5- Algebraic equations of the DFIG (5), (6), and (52).

6- Algebraic equations of the PEC controller (16), (18), (19), (22), (24), (25), (27), (30), (31) ,(35), and (36).

7- Algebraic equations of the drive train system of the wind turbine ((42)-(46)).

8- Algebraic equations of the load flow ((53)(58)).

$$
\begin{aligned}
& X=\left[X_{D F \mid G}, X_{\text {control }}, X_{\text {Drive -trane }}, X_{\text {pitch }}\right]_{1 \times 16} \\
& X_{\text {DFIG }}=\left[I_{D s}, I_{Q s}, e_{D}^{\prime}, e_{Q}^{\prime}\right] \\
& X_{\text {control }}=\left[X_{1}, X_{2}, X_{3}, X_{4}, V_{d c}, X_{5}, X_{6}, X_{7}\right] \\
& X_{\text {Drive-trine }}=\left[\omega_{t}, \omega_{r}, \theta_{t w}\right] \\
& X_{\text {pitch }}=[\beta]
\end{aligned}
$$

$$
\begin{aligned}
& y=\left[Y_{D F / G}, Y_{\text {control }}, Y_{\text {Dive -trane }}, Y_{\text {bus }}\right]_{1 \times 24} \\
& Y_{D F / G}=\left[V_{D r}, V_{Q r}, T_{\theta}\right] \\
& Y_{\text {contol }}=\left[V_{D r}, V_{Q r}^{*}, I_{D r}, I_{Q r}, I_{D r}\right. \\
& \left., I_{Q r}^{*}, V_{D f}^{*}, V_{Q f}, I_{D f}, I_{Q f}, I_{D f}\right] \\
& Y_{\text {Drive -ttine }}=\left[\lambda, C_{p}, T_{m}\right] \\
& Y_{\text {bus }}=\left[\left|V_{3}\right|, \theta_{3},\left|V_{2}\right|, \theta_{2},\left|V_{1}\right|\right]
\end{aligned}
$$

Where, $x$ is vector of state parameters, $y$ is vector of algebraic parameters, $X$ is state parameters and $Y$ is algebraic parameters.

\section{Dynamic simulation of the CSS}

The block diagram of the CSS is shown in Figure 11. This model includes grid, wind turbine and load bus. The load bus is located between the grid and the wind turbine bus. Obtained results by eigenvalue analysis of CSS dynamic model are 


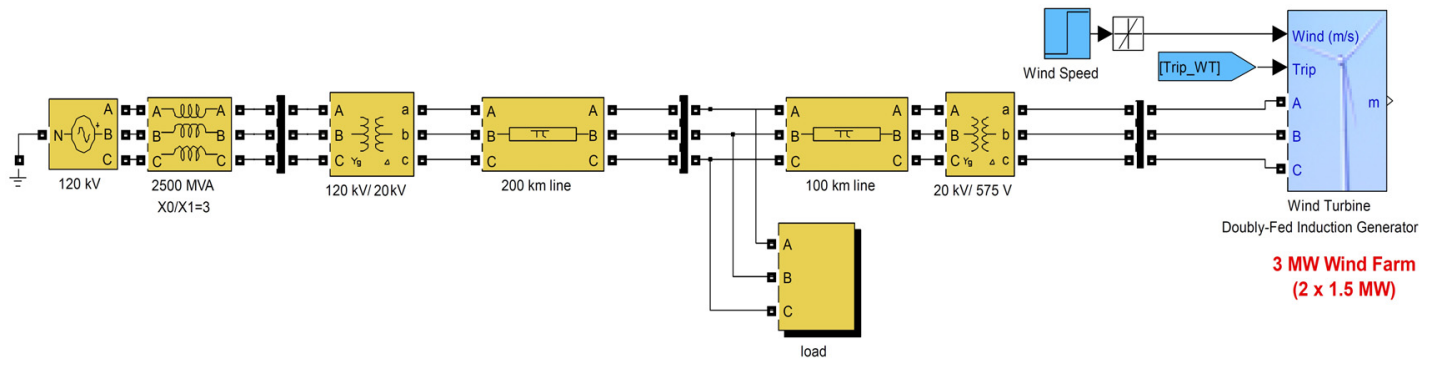

Figure 11. Block diagram of the CSS in Matlab Simulink.

verified by Matlab simulation. As stability factor, these results have been investigated for demonstrating the impact of different parameters variations on power and voltage of wind turbine and load bus.

\section{CSS stability based on eigenvalue analysis}

Eigenvalue analysis is used to analyze the dynamic stability of the CSS, hence, the description equations of the CSS are linearized around an operating point $\left(\mathrm{x}_{0}, \mathrm{y}_{0}\right)[17]$.

$$
\begin{gathered}
\Delta x=A \Delta x+B \Delta y \\
0=C \Delta x+D \Delta y
\end{gathered}
$$

$A, B, C$ and $D$ are Jacobian matrices. All elements of the Jacobian matrices are presented in Appendix. By inserting $\Delta y=-D^{-1} C \Delta x$ in Equation 61 , the system matrix of the CSS can be determined:

$$
\begin{aligned}
\Delta x & =\underbrace{\left(A-B D^{-1} C\right)}_{A_{\text {sys }}} \Delta x \\
A_{\text {sys }} & =A-B D^{-1} C
\end{aligned}
$$

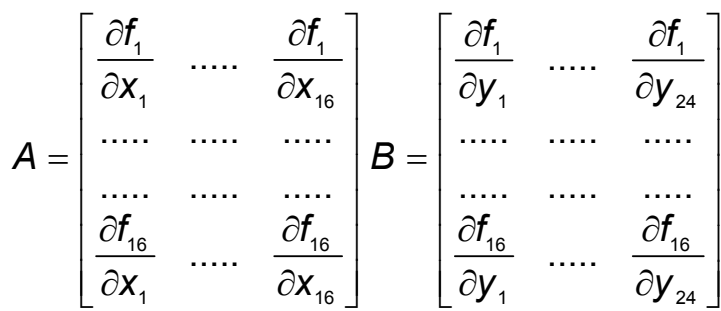

$$
\begin{aligned}
& C=\left[\begin{array}{ccc}
\frac{\partial g_{1}}{\partial x_{1}} & \ldots . . & \frac{\partial g_{1}}{\partial x_{16}} \\
\cdots . . & \ldots . . & \ldots . . \\
\ldots . . & \ldots . . & \ldots . . \\
\frac{\partial g_{24}}{\partial x_{1}} & \ldots . . & \frac{\partial g_{24}}{\partial x_{16}}
\end{array}\right] D=\left[\begin{array}{ccc}
\frac{\partial g_{1}}{\partial y_{1}} & \ldots . . & \frac{\partial g_{1}}{\partial y_{24}} \\
\ldots . . & \ldots . . & \ldots . . \\
\ldots . . & \ldots . . & \ldots . . \\
\frac{\partial g_{24}}{\partial y_{1}} & \ldots . . & \frac{\partial g_{24}}{\partial y_{24}}
\end{array}\right]
\end{aligned}
$$

$A_{\text {sys }}$ is system matrix of CSS. The system stability is studied by examining the eigenvalues of $A_{s y s}$ around an operating point. Eigenvalue of CSS is presented in Table1 for an operating point. In this table, oscillation frequency and damping ratio is calculated too. Table1 shows that CSS is stable for initial values of reference table. 


\begin{tabular}{c|ccc}
\hline Eigenvalue & $\sigma \pm j \omega$ & $f$ & $\xi$ \\
\hline$\lambda_{1,2}$ & $-8.9671 \pm 22.9589 \mathrm{i}$ & \pm 3.6540 & 0.3638 \\
$\lambda_{3,4}$ & $-8.1211 \pm 8.3643 \mathrm{i}$ & \pm 1.3312 & 0.6966 \\
$\lambda_{5,6}$ & $-1.1630 \pm 4.1452 \mathrm{i}$ & \pm 0.6597 & 0.2701 \\
$\lambda_{7}$ & -6.7268 & 0 & 1.0000 \\
$\lambda_{8,9}$ & $-4.1987 \pm 2.9759 \mathrm{i}$ & \pm 0.4736 & 0.8159 \\
$\lambda_{10,11}$ & $-1.4409 \pm 2.4845 \mathrm{i}$ & \pm 0.3954 & 0.5017 \\
$\lambda_{12}$ & -0.7669 & 0 & 1.0000 \\
$\lambda_{13}$ & -1.5307 & 0 & 1.0000 \\
$\lambda_{14}$ & -2.2416 & 0 & 1.0000 \\
$\lambda_{15}$ & -3.0844 & 0 & 1.0000 \\
$\lambda_{16}$ & -4.0128 & 0 & 1.0000 \\
\hline
\end{tabular}

Table 1. Eigenvalues of the CSS.

\section{Impact of network parameters}

In this subsection, impact of network parameters such as load power, power factor of load, the inductance and resistance of line transmission, has been investigated on CSS eigenvalues displacement. Obtained results from eigenvalues analyzing have been compared to simulation results.

\subsection{Influence of the load}

Figure12 shows the influence of the load power on the displacement of eigenvalues of the CSS. Load variations are considered in sub-synchronous, normal and sup-synchronous speed modes as ascending and its limitation is $2 p . u<P_{\text {load }}<5 p . u$, while keeping all other parameters at their initial values. In low levels of load power, eigenvalues of CSS are located in left half-plane and CSS is stable, gradually by increasing in load power, 4 eigenvalues displace toward right half-plane. For load changes in the sup-synchronous mode, the initial values $\lambda_{5,6}$ are closer to the imaginary axis and by increasing load, instability happens faster in CSS than in the other two modes.

Eigenvalues in Figure 12 are $\lambda_{5}, \lambda_{6}$ and $\lambda_{12}$,cause the system to be instable. $\lambda_{5}$ and $\lambda_{6}$ have constant imaginary values in left half-plane. By passing from left the half-plane to the right half-plane, the imaginary part of two values and the real part have been changed. $\lambda_{5}, \lambda_{6}$ are complex quantities. Thus, the system will be in oscillatory instability status. In reality, it can be said, that these eigenvalues are able to cause voltage collapse phenomena.

Eigenvalues with positive real part cause instability with no oscillation and analytic eigenvalues with positive real part cause oscillatory instability in the CSS.

Oscillations frequency and damping factor of eigenvalues, $\lambda_{5}, \lambda_{6}$ and $\lambda_{12}$ for different loads $2 p . u$, 3.5p.u and $4 p . u$ are characterized in Tables 2 and 3 . For load values over than 3.5p.u, additionally $\lambda_{5,6}$, eigenvalue $\lambda_{12}$, causes instability. In Table 3 that comprises oscillations frequency and damping factor, it is expected for eigenvalues $\lambda_{5,6}$ and $\lambda_{12}$ that, oscillatory instability and instability with no oscillation accrue. By increasing real power in load bus, mechanical input power of turbine needs to be changed. Therefore, it can be said, that real power increasing is effective on power transmission system mechanical modes.

\begin{tabular}{c|ccc}
\hline Eigenvalue & $P=2 p . u$ & $P=3.5 p . u$ & $P=4 p . u$ \\
\hline$\lambda_{5}$ & $-1.1630+4.1452 i$ & $2.4678+3.2352 i$ & $0.6581+0.8425 i$ \\
$\lambda_{6}$ & $-1.1630-4.1452 i$ & $2.4678-3.2352 i$ & $0.6581-0.8425 i$ \\
$\lambda_{12}$ & -0.7669 & -0.2832 & 8.9119 \\
\hline
\end{tabular}

Table 2. Effective eigenvalues on instability with load changing in normal mode.

\begin{tabular}{c|cc|cc|cc}
\hline \multirow{2}{*}{ Eigenvalue } & \multicolumn{2}{|c|}{$P=2 p . u$} & \multicolumn{2}{c|}{$P=3.5 p . u$} & \multicolumn{2}{c}{$P=4 p . u$} \\
\cline { 2 - 7 } & $f$ & $\xi$ & $f$ & $\xi$ & $f$ & $\xi$ \\
\hline$\lambda_{5,6}$ & 0.6597 & 0.2701 & 0.5149 & -0.6065 & 0.1341 & -0.6156 \\
$\lambda_{12}$ & 0 & 1 & 0 & 1 & 0 & 1 \\
\hline
\end{tabular}

Table 3. Oscillations frequency and damping factor of effective eigenvalues on instability in normal mode. 


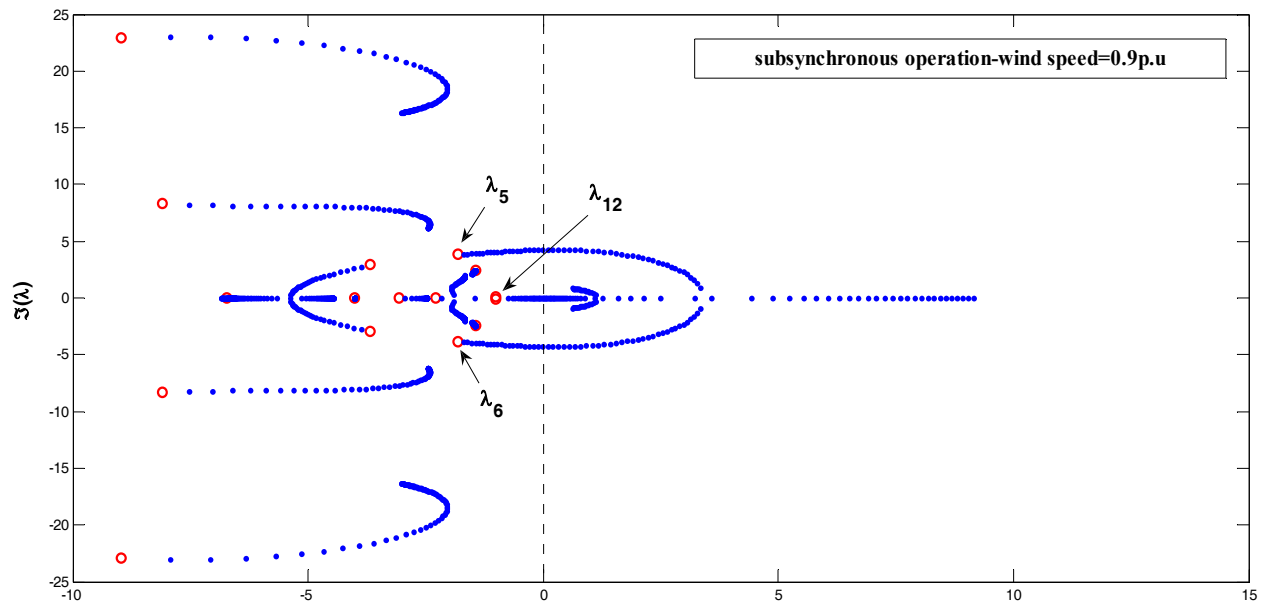

$\Re(\lambda)$

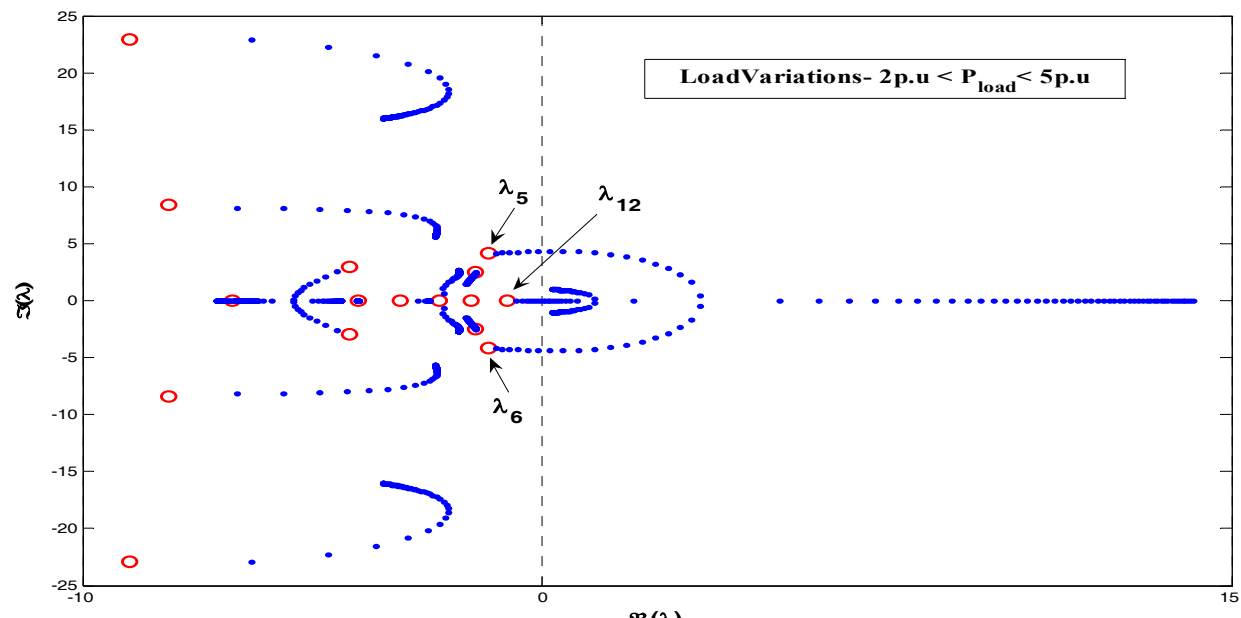

$\Re(\lambda)$

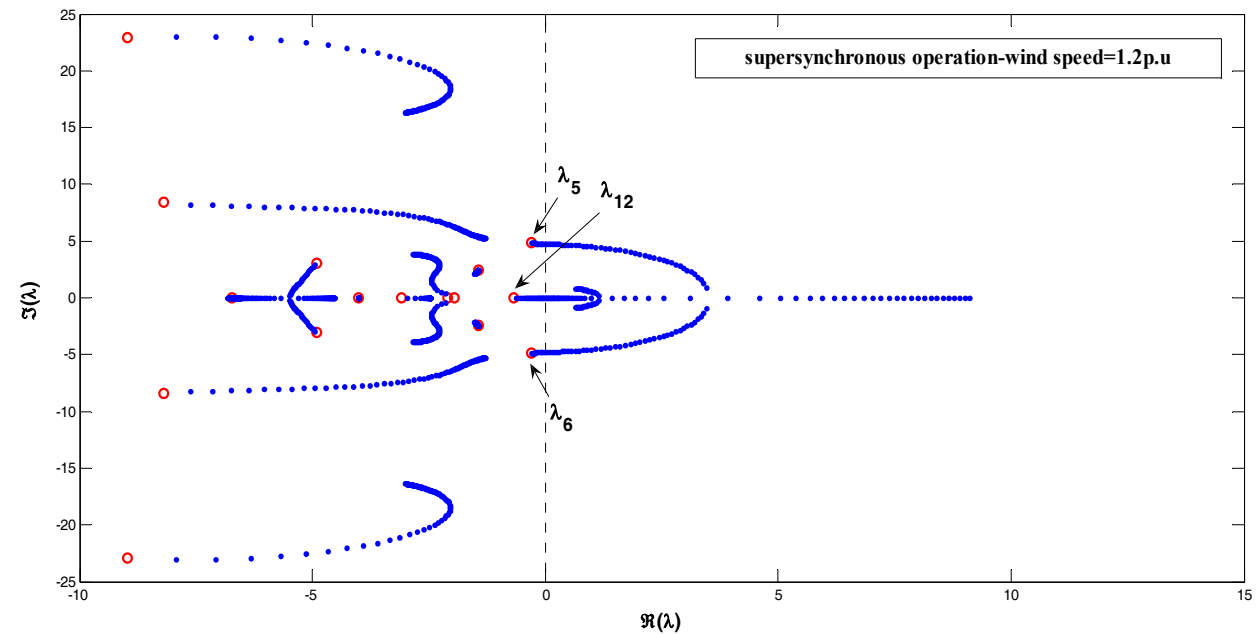

Figure 12. Influence of the load power on the stability of CSS in three modes operation: a) subsynchronous, b) normal, c) super-synchronous. 


\subsection{Influence of the load power factor}

Figure 13 shows the influence of the load power factor or consuming reactive power of load in load bus. Power factor variations for passive load have been done for $0.2<p f<0.9$ in three operation modes: a-sub-synchronous, b-normal, c-supsynchronous. During the power factor variations, other parameters assume in initial values. By decreasing power factor or more consuming
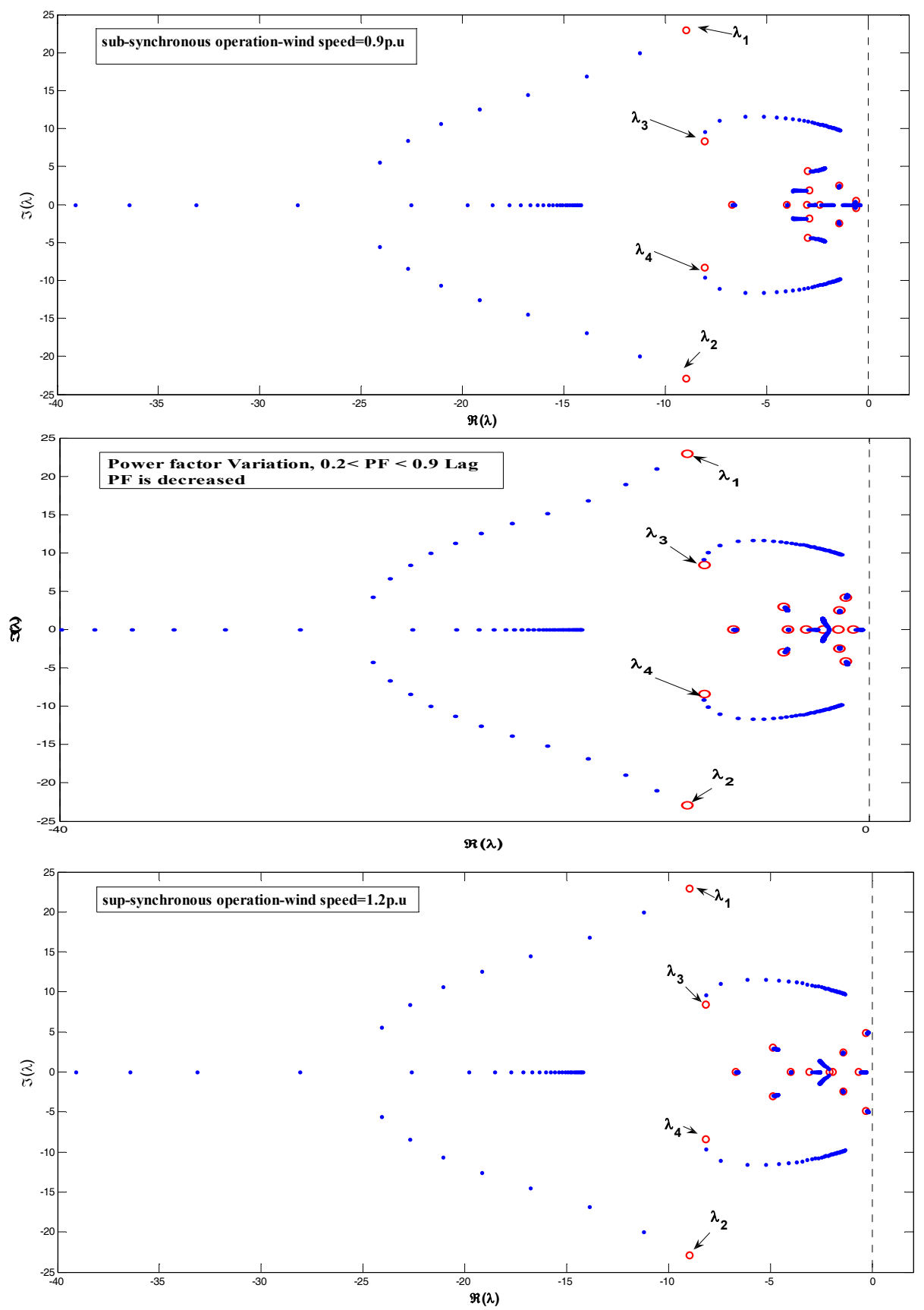

Figure 13. Influence of the load power factor on stability in three operation modes: a) subsynchronous, b) normal, c) super-synchronous. 


\begin{tabular}{c|ccc}
\hline Eigenvalue & $p f=0.9 p . u$ & $p f=0.5 p . u$ & $p f=0.2 p . u$ \\
\hline$\lambda_{1}$ & $-8.9671+22.9589 i$ & -41.4156 & -60.5309 \\
\hline$\lambda_{2}$ & $-8.9671-22.9589 i$ & -17.1520 & -14.3990 \\
\hline$\lambda_{4.3}$ & $-8.1211 \pm 8.3643 i$ & $-2.6555 \pm 10.7277 i$ & $-1.4921 \pm 9.8937 i$ \\
\hline
\end{tabular}

Table 4. Effective eigenvalues on instability with power factor changing.

reactive power, sensitive eigenvalues $\lambda_{1,2}$ and $\lambda_{3,4}$ move toward instability border. Four eigenvalues of CSS that are more sensitive to power factor variations are illustrated in Figure 13. The most effect of power factor variations are on the 2 eigenvalues, $\lambda_{3,4}$. Gradually by power factor decreasing, negative damping factor move to stability border.Table4 shows eigenvalues that are affected from power factor variation for three states, $0.9,0.5$ and 0.2 in normal mode. For values 0.5 and $0.2, \lambda_{1}$ and $\lambda_{2}$ just have negative real value.

Influence of load power and power factor on bus voltage validated through a dynamic simulation in Matlab Simulink. Simulation model is similarly to CSS and comprises 3 buses: grid, load and DFIG wind turbine. Figure 14 shows the impact of active power and power factor variations of load on the voltages of the grid, load and DFIG buses.

Figure 14 demonstrates, by increasing the active and reactive power consumption of load, voltage level of 3 buses decrease intensely. Thus voltage factor with these variations can be considered as stability criterion of simulated system. Considering results obtained in eigenvalue analysis, it can be said, that the eigenvalues which cause instability in system, has became apparent voltage instability in simulated system.

\subsection{Influence of line inductance}

Figure 15 shows the influence of the line inductance on the eigenvalues of CSS. Line inductance variations are considered in subsynchronous, normal, sup-synchronous operation modes as ascending, and its limitation is $\left(0.0088<X_{\text {line }}<0.012\right)$. All other parameters have kept at their initial values. With increasing line inductance, $\lambda_{1}$ displace to unstable area and makes the system unstable. By considering [17], about maximum power transmitting, it can be said, that line inductance increasing leads to decreases of maximum transmitted power from the DFIG to the network so it matches the obtained results from the eigenvalues analysis.

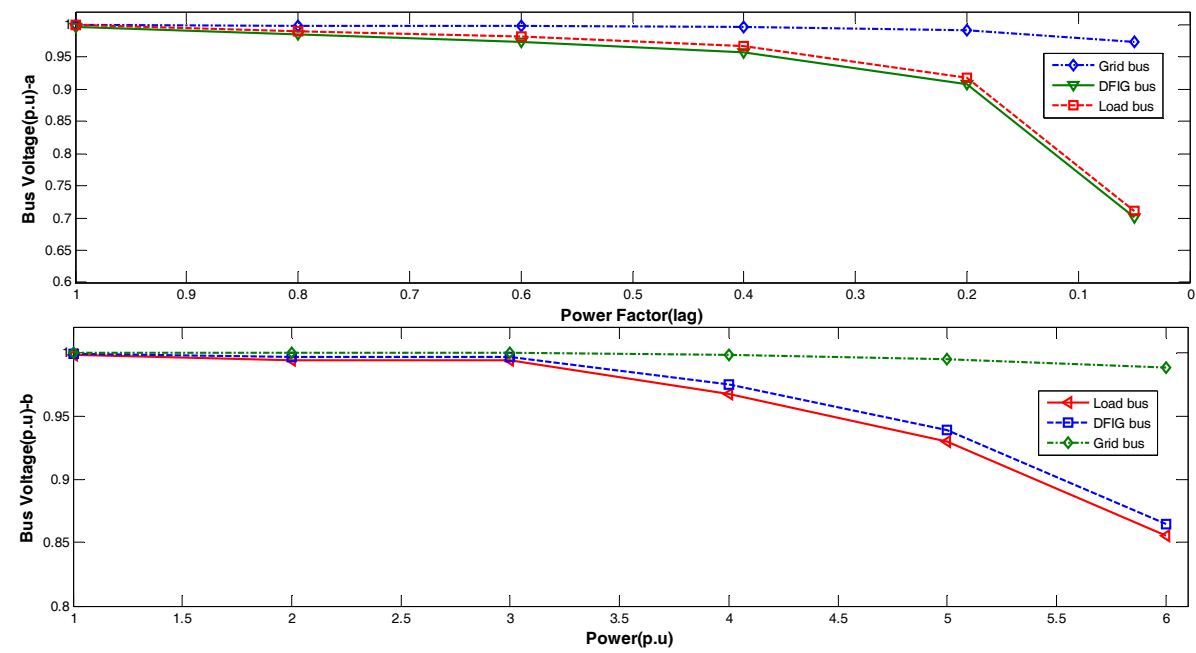

Figure 14. a) The impact of power factor variations on the voltages of buses, b) The impact of power variations on the voltages of buses. 


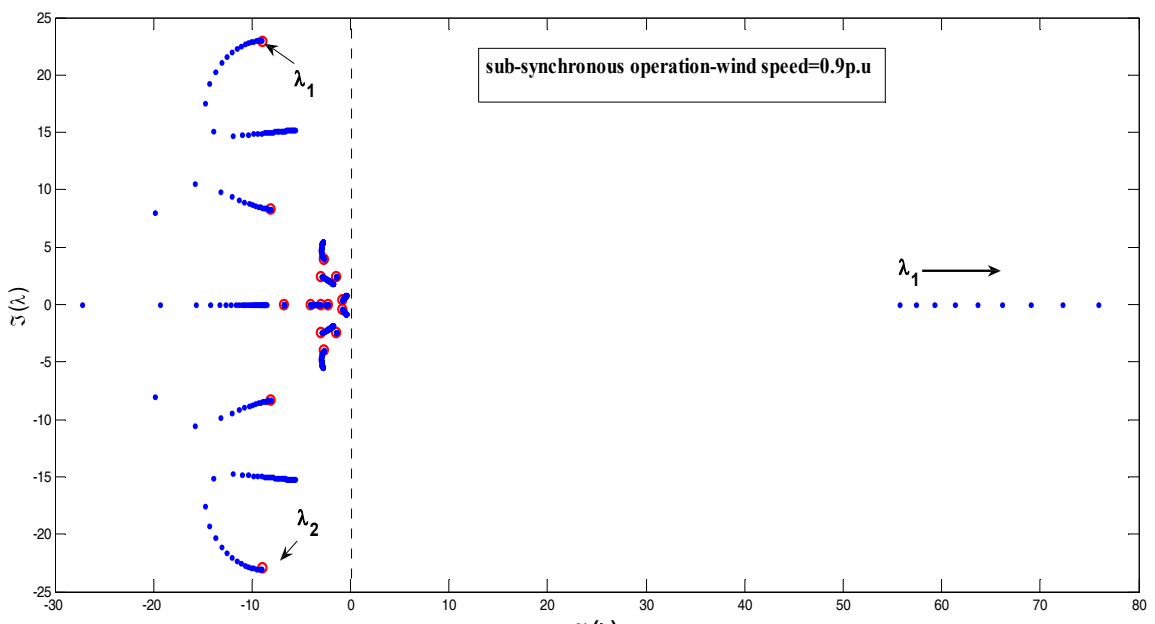

$\Re(\lambda)$
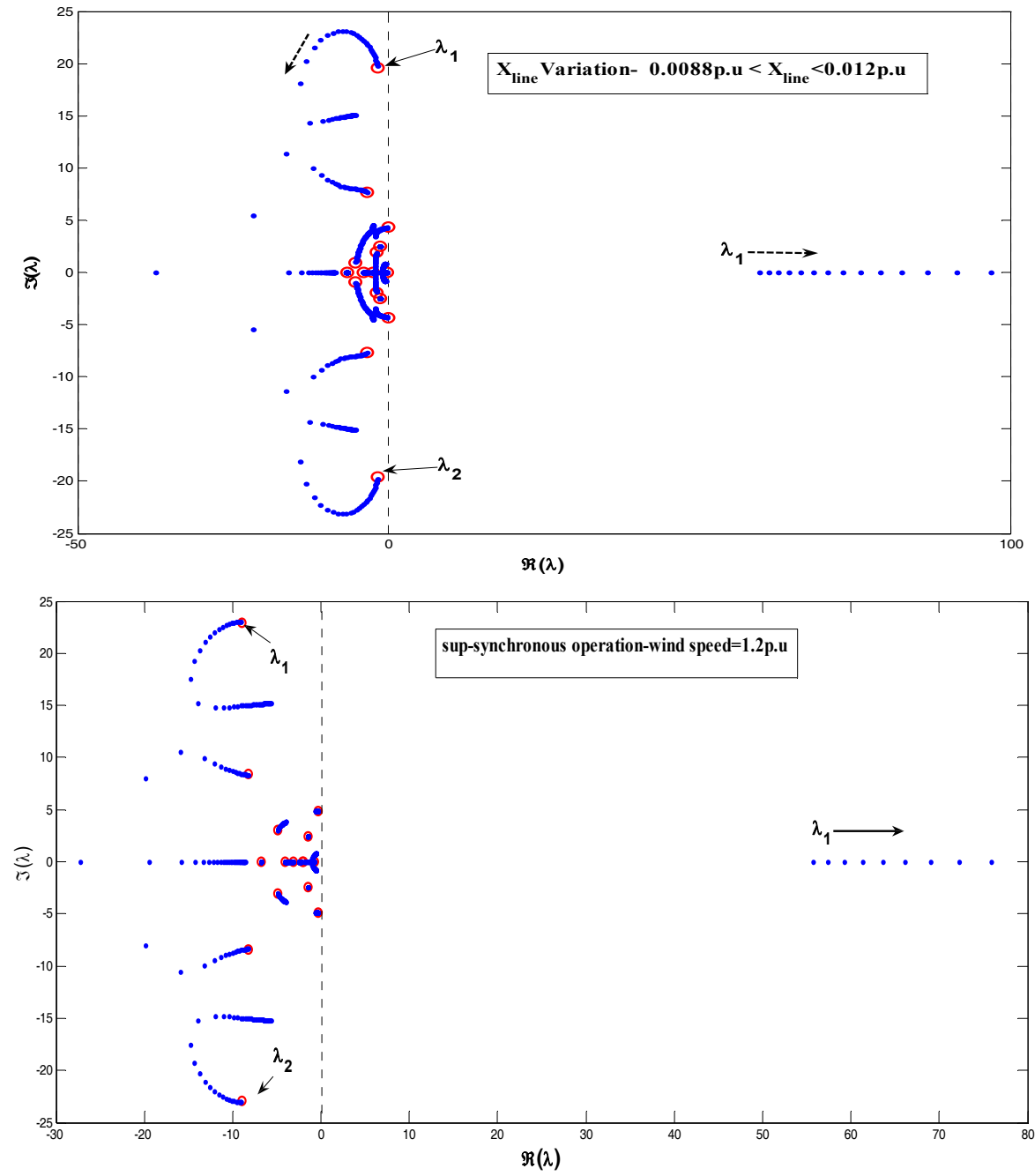

Figure 15. Influence of line inductance on system stability in three operation modes: a) subsynchronous, b) normal, c) super-synchronous. 

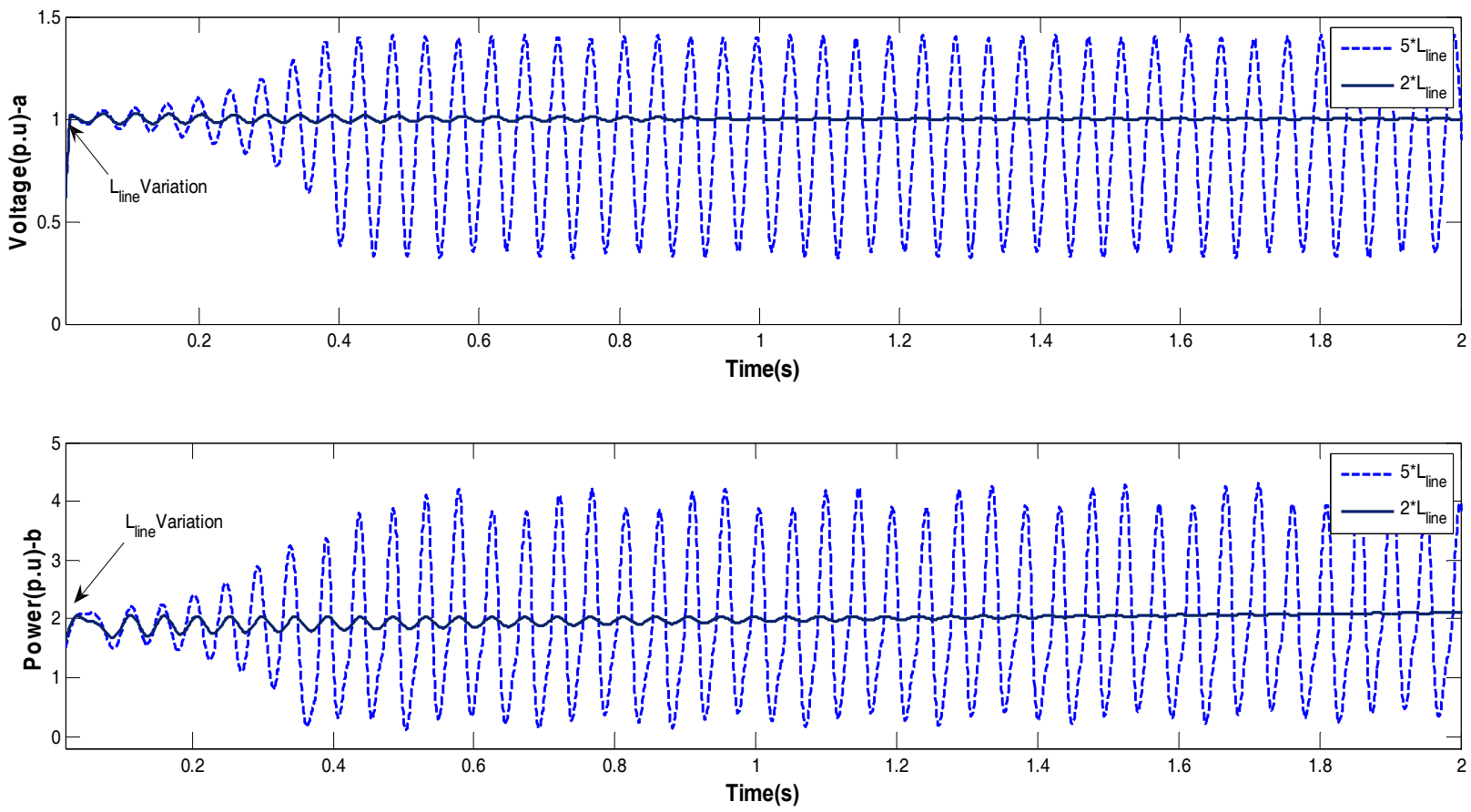

Figure 16. Impact of line inductance changes on a) voltage and b) active power of load.

Figure 16 presents the impact of line inductance changes on stability by dynamic simulation in Matlab Simulink. The impact of line parameter changes in network side and WT on stability is equal. Thereby, in presented results, just the impact of line parameters in DFIG side has been investigated. The impact of the line inductance changes on active power and voltage of load has been exposed and considered as criterion of systems stability.

Line inductance variations have been considered for $2^{*} L_{\text {line }}$ and $5^{*} L_{\text {line }}$. for $2^{*} L_{\text {line }}$, active power and voltage of load bus become stable after oscillation cycles, in the next stage, increasing line inductance to $5^{*} L_{\text {line }}$, that causes to oscillate the active power and voltage of load. Consequently, it results in system instability.

Line inductance increasing, changes the power transmission from the DFIG to the network, and cause excitation system to oscillation modes. By analyzing eigenvalue, it can be concluded about line inductance changing that $\lambda_{1}$ culminated this instability.

\subsection{Influence of the line resistance}

Figure 17 shows the influence of the line resistance on the system stability. Resistance variations are considered as ascending, and its limitation is 0.001 p.u $<R_{\text {line }}<0.0065$ p.u. Here the variations are considered for three modes too, while keeping all other parameters at their initial values. Considering the way line resistance increases, lead to displacement $\lambda_{1}$ to unstable area and causes system instability. The important point in this state is eigenvalue variation process which is similar to influence of $X_{\text {line }}$ variations. In both states eigenvalue $\lambda_{1}$ lead to system instability. Figure 18 shows the impact of the line resistant on system stability in Matlab Simulink. The influence of the line resistance variations on power of load bus has been demonstrated and considered as criterion of systems stability. 

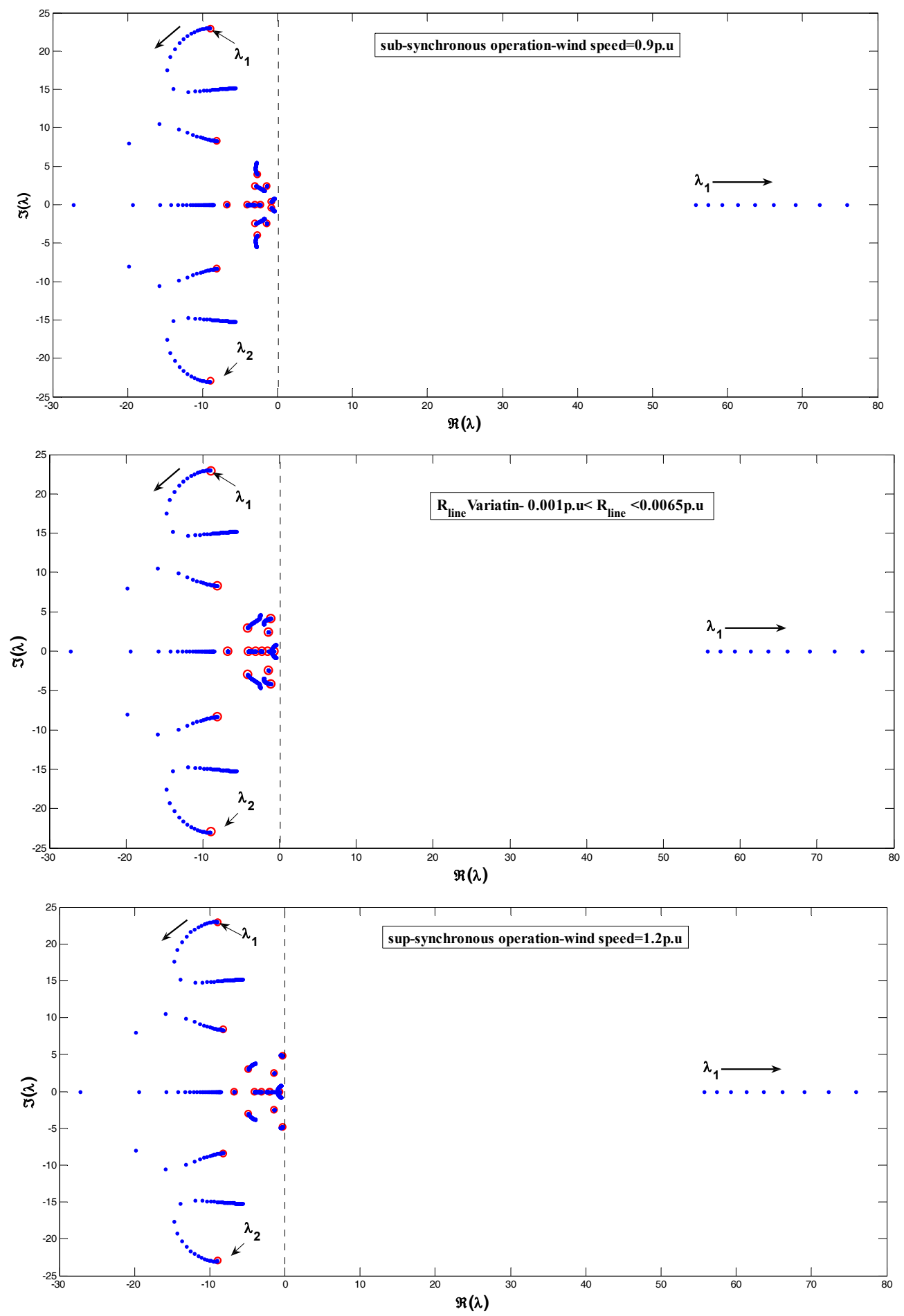

Figure 17. Influence of line resistance on stability in three operation modes: a) subsynchronous, b) normal, c) super-synchronous. 

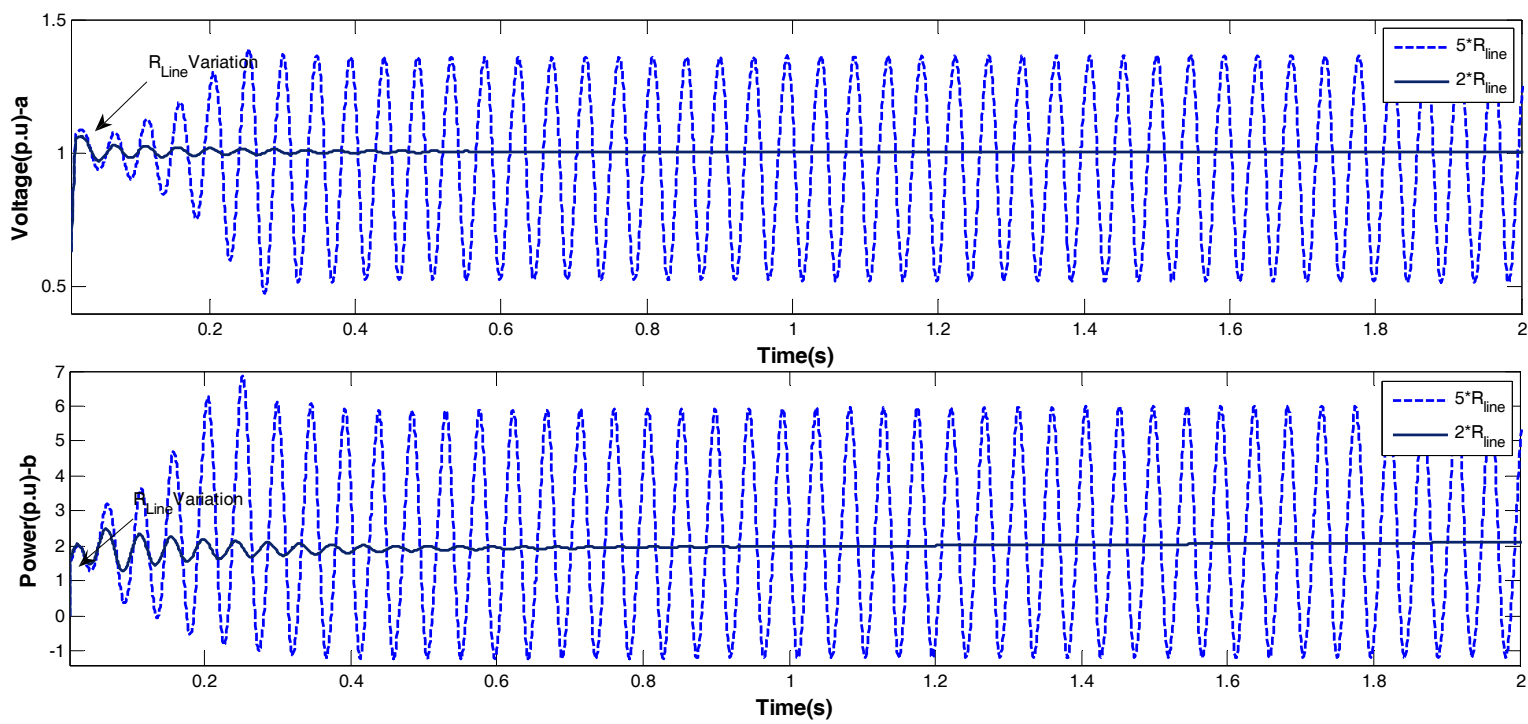

Figure 18. Impact of line resistance changes on system stability.

\section{Conclusion}

In this paper, a dynamic model of a power system connected to a DFIG wind turbine of sixteenthorder has been presented by means of the eigenvalue analysis. The influence of network parameters on the system dynamic stability has been investigated in three operation modes: subsynchronous, normal and super-synchronous. The results obtained show the nature of instability in simulation studies. Considering the results obtained from the eigenvalue analysis, by increasing real power of load, mechanical modes related to DFIG caused system instability by excitation eigenvalue $\lambda_{5,6}$. Also, it was demonstrated that variation of transmission line parameters (line inductance and resistance) has similar effect on eigenvalue $\lambda_{1}$. The results show in subsynchronous mode, the system is more stable with respect to parameter sensitivity analysis. Besides, dynamic simulation results influence of considerable parameters variations for different states have been verified. In this paper, similarly to other studies about voltage stability, eigenvalue $\lambda_{12}$ causes voltage instability in CSS.

\section{References}

[1] C. Wang et al, "A Survey on Wind Power Technologies in Power Systems," Power Engineering Society General Meeting., Tampa, FL., 2007, pp.1-6.

[2] T. Ackermann, "Wind Power in Power Systems", John Wiley \& Sons,pp.523-554,2005.

[3] J.G.M.Herbert et al, "A Review of Wind Energy Technologies", Renewable and Sustainable Energy Reviews, Vol.11, no. 6, pp. 1117-1145,2007.

[4] H. R. Najafi et al, "The Impact of Electric wind farm operation with Doubly Fed Induction Generator (DFIG) on electric power grid," International Conference on Electrical Engineering., Okinawa, Japan.,2008,pp.36-42.

[5] Ch. Eping et al, "Impact of Large Scale Wind Power on Power System Stability". Power System Conference, 2008. MEPCON 2008. 12th International Middle-East., Aswan.,2008,pp.630-636.

[6] H.A. Pulgar-Painemal and P.W. Sauer, "Power system modal analysis considering doubly-fed induction generators," Bulk Power System Dynamics and Control Symposium., Rio de Janeiro.,2010, pp. 1-7.

[7] NAJAFI, Hamid Reza et al, "Sensitivity Study of Parameters influencing Large-Disturbance Stability of Wind-Farm implemented with DFIG," International Journal of Electrical Engineering, vol.17, no.2,pp.50-65, 2010. 
[8] W. Qiao, "Dynamic Modeling and control of Doubly Fed Induction Generators Driven by Wind Turbines," Power Systems Conference and Exposition.,Seattle, WA.,2009, pp.1-7.

[9] V. Akhmatov, "Analysis of dynamic behavior of electric power systems with large amount of wind power," Ph.D. dissertation, Technical Univ. Denmark, Lyngby, Denmark, 2003.

[10] J. G. Slootweget al, "Dynamic modeling of a wind turbine with doubly fed induction generator," Power Engineering Society Summer Meeting., Vancouver, BC.,2001, pp.644-649.

[11] Yateendra Mishra et al, "Small-Signal Stability Analysis of a DFIG-Based Wind Power System under Different Modes of Operation" IEEE Transactions on Energy Conversion, vol.24, no.4,pp. 972-982, 2009.

[12] Lihui Yang et al,"Oscillatory Stability and Eigenvalue Sensitivity Analysis of A DFIG Wind Turbine System"., IEEE Transactions on Energy Conversion, vol.26, no.1,pp.328-339, 2011.

[13] L. Yang et al, "Optimal controller design of a doubly-fed induction generator wind turbine system for small signal stability enhancement" IET Gener. Transm. Distrib., vol.4, no. 5, pp. 579-597, 2010.

[14] F. Mei and B. Pal, "Modal analysis of gridconnected doubly fed induction generators," IEEE Trans. Energy Conv., vol. 22, no.3, pp. 728-736,. 2007.

[15] Y. Lei, A. Mullane et al, "Modeling of the wind turbine with a doubly fed induction generator for grid integration studies," IEEE Trans. Energy Convers., vol. 21, no.1, pp. 257-264, 2006.

[16] AliAsghar.Samadi, "Dynamic modeling of variable speed wind turbine implemented with Doubly Fed Induction Generator (DFIG), " Thesis of M. Sc. Degree in Electrical Engineering (Power), University of Birjand, Faculty of Engineering, June-2009.

[17] P. Kundur, "Power system stability and control". New York, McGraw-Hill, 1994,pp.1021-1161.

[18] P. S. Sauer and M. A. Pai, "Power System Dynamics and Stability”, Prentice-Hall, 1998,pp.270-346.

[19] B. Hopfensperger et al, "Stator-flux-oriented control of a doubly-fed induction machine with and without position encoder," IEE Proc. Electr. Power Appl., vol.147 no.4, pp. 241-250, 2000.
[20] Jan Machowski, Janusz W. Bialek, James R. Bumby, "power system dynamics stability and Control", John Wiley \& Sons, 2008,pp.209-343..

\section{Appendix}

\section{A- Data of CSS}

\begin{tabular}{|c|c|}
\hline \multicolumn{2}{|l|}{ Wind turbine } \\
\hline Damping factor axis(D)=1.5 & $\begin{array}{c}\text { Turbine } \\
\text { constant }\left(H_{t}\right)=3 \mathrm{~s}\end{array}$ \\
\hline & $\begin{array}{c}\text { Generator } \\
\text { constant }\left(H_{g}\right)=0.5 \mathrm{~s}\end{array}$ \\
\hline \multicolumn{2}{|l|}{ DFIG } \\
\hline $\begin{array}{l}\text { Rotor } \\
\text { inductance }\left(L_{r}\right)=0.156 \mathrm{p} . u\end{array}$ & Rotor resistance $\left(R_{r}\right)=0.005 p . u$ \\
\hline \multirow[t]{2}{*}{ Inductance $(\mathrm{Lm})=2.9 \mathrm{p} . \mathrm{u}$} & $\begin{array}{l}\text { Stator } \\
\text { resistance }\left(R_{s}\right)=0.0076 \mathrm{p} . u\end{array}$ \\
\hline & $\begin{array}{l}\text { Stator } \\
\text { inductance }\left(L_{s}\right)=0.171 p . u\end{array}$ \\
\hline \multicolumn{2}{|l|}{ Converter } \\
\hline \multirow[t]{2}{*}{$\begin{array}{l}\text { Filter } \\
\text { resistance }\left(R_{\mathrm{f}}\right)=0.015 \mathrm{p} . \mathrm{u}\end{array}$} & Dc link capacitor $(\mathrm{c})=0.001 \mathrm{p} . \mathrm{u}$ \\
\hline & Filter inductance $\left(\mathrm{L}_{\mathrm{f}}\right)=0.1 \mathrm{p} . \mathrm{u}$ \\
\hline \multicolumn{2}{|l|}{ Controller parameters } \\
\hline \multirow{2}{*}{\multicolumn{2}{|c|}{$\begin{array}{ccc}\mathrm{K}_{\mathrm{p} 1}=1, \mathrm{~K}_{\mathrm{i} 1}=100, & \mathrm{~K}_{\mathrm{p} 2}=0.3, \mathrm{~K}_{\mathrm{i} 2}=8, & \mathrm{~K}_{\mathrm{p} 3}=1.25, \mathrm{~K}_{\mathrm{i} 3}=300, \\
\mathrm{~K}_{\mathrm{p} 4}=0.3, \mathrm{~K}_{\mathrm{i} 4}=8, \mathrm{~K}_{\mathrm{p} 5}=0.002, \mathrm{~K}_{\mathrm{i} 5}=0.05, \mathrm{~K}_{\mathrm{p} 6}=1, \mathrm{~K}_{\mathrm{i} 6}=100, \mathrm{~K}_{\mathrm{p} 7}=1, \mathrm{~K}_{\mathrm{i} 7}=100,\end{array}$}} \\
\hline & \\
\hline Power factor $(\mathrm{pf})=0.8$ & Real power $=2 \mathrm{MW}$ \\
\hline
\end{tabular}

\section{Elements of Jacobian matrices}

Matrix A

$$
\begin{aligned}
& \frac{\partial f_{1}}{\partial X_{1}}=-\left[\frac{\omega_{s}}{X_{s}^{\prime}}\left(R_{s}+\frac{X_{s}-X_{s}^{\prime}}{\omega_{s} T_{s}^{\prime}}\right)\right], \frac{\partial f_{1}}{\partial X_{2}}=\left(2 \omega_{s}-\omega_{r}\right), \\
& \frac{\partial f_{1}}{\partial X_{3}}=\left[\frac{\omega_{r}}{X_{s}^{\prime}}\right], \frac{\partial f_{1}}{\partial X_{4}}=-\left[\frac{1}{X_{s}^{\prime} T_{o}^{\prime}}\right], \\
& \frac{\partial f_{1}}{\partial X_{14}}=-I_{Q s}+\left[\frac{e_{D}^{\prime}}{X_{s}^{\prime}}\right], \frac{\partial f_{2}}{\partial X_{1}}=-\left(2 \omega_{s}-\omega_{r}\right), \\
& \frac{\partial f_{2}}{\partial X_{2}}=-\left[\frac{\omega_{s}}{X_{s}^{\prime}}\left(R_{s}+\frac{X_{s}-X_{s}^{\prime}}{\omega_{s} T_{s}^{\prime}}\right)\right], \\
& \frac{\partial f_{2}}{\partial X_{3}}=\left[\frac{1}{X_{s}^{\prime} T_{o}^{\prime}}\right], \frac{\partial f_{2}}{\partial X_{4}}=\left[\frac{\omega_{r}}{X_{s}^{\prime}}\right], \frac{\partial f_{2}}{\partial X_{14}}=-I_{D s}+\left[\frac{e_{Q}^{\prime}}{X_{s}^{\prime}}\right] \\
& \frac{\partial f_{3}}{\partial X_{2}}=\left(\frac{X_{s}-X_{s}^{\prime}}{T_{o}^{\prime}}\right), \frac{\partial f_{3}}{\partial X_{3}}=\left(-\frac{1}{T_{o}^{\prime}}\right), \\
& \frac{\partial f_{3}}{\partial X_{4}}=-2\left(\omega_{s}-\omega_{r}\right), \frac{\partial f_{3}}{\partial X_{14}}=-2 e_{Q}^{\prime}
\end{aligned}
$$


$\frac{\partial f_{4}}{\partial X_{1}}=\left(\frac{X_{s}-X_{s}^{\prime}}{T_{o}^{\prime}}\right), \frac{\partial f_{4}}{\partial X_{3}}=-2\left(\omega_{s}-\omega_{r}\right)$

$\frac{\partial f_{4}}{\partial X_{4}}=\left(-\frac{1}{T_{0}^{\prime}}\right), \frac{\partial f_{4}}{\partial X_{14}}=-2 e_{Q}^{\prime}$

$\frac{\partial f_{5}}{\partial X_{1}}=-V_{D s}, \frac{\partial f_{5}}{\partial X_{2}}=-V_{Q s}, \frac{\partial f_{7}}{\partial X_{1}}=V_{Q s}$,

$\frac{\partial f_{7}}{\partial X_{2}}=-V_{D s}, \frac{\partial f_{9}}{\partial X_{12}}=-1, \frac{\partial f_{12}}{\partial X_{12}}=\frac{-1}{C V_{d c}^{2}}\left(V_{r} I_{r}-V_{f} I_{f}\right)$

$\frac{\partial f_{13}}{\partial X_{13}}=-\frac{D}{2 H_{t}}, \frac{\partial f_{13}}{\partial X_{14}}=\frac{D}{2 H_{t}}, \frac{\partial f_{13}}{\partial X_{15}}=-\frac{K}{2 H_{t}}$,

$\frac{\partial f_{14}}{\partial X_{13}}=\frac{D}{2 H_{g}}, \frac{\partial f_{14}}{\partial X_{14}}=-\frac{D}{2 H_{g}}, \frac{\partial f_{14}}{\partial X_{15}}=\frac{K}{2 H_{g}}$,

$\frac{\partial f_{15}}{\partial X_{13}}=1, \frac{\partial f_{15}}{\partial X_{14}}=-1, \frac{\partial f_{16}}{\partial X_{14}}=\frac{K_{\text {pitch }}}{T_{\text {pitch }}}, \frac{\partial f_{16}}{\partial X_{16}}=-\frac{1}{T_{\text {pitch }}}$

\section{Matrix $B$}

$\frac{\partial f_{1}}{\partial Y_{6}}=\left[\frac{\omega_{s}}{X_{s}^{\prime}} \frac{L_{m}}{L_{r r}}\right], \frac{\partial f_{1}}{\partial Y_{19}}=\frac{\omega_{s}}{X_{s}^{\prime}}\left|V_{3}\right| \sin \theta_{3}, \frac{\partial f_{2}}{\partial Y_{3}}=\left[\frac{\omega_{s}}{X_{s}^{\prime}} \frac{L_{m}}{L_{r r}}\right]$,

$\frac{\partial f_{2}}{\partial Y_{19}}=-\frac{\omega_{s}}{X_{s}^{\prime}}\left|V_{3}\right| \cos \theta_{3}, \frac{\partial f_{3}}{\partial Y_{3}}=-\left[\omega_{s} \frac{L_{m}}{L_{r r}}\right]$,

$\frac{\partial f_{4}}{\partial Y_{6}}=\left[\omega_{s} \frac{L_{m}}{L_{r r}}\right], \frac{\partial f_{5}}{\partial Y_{19}}=\left|V_{3}\right| \sin \theta_{3} I_{D s}-\left|V_{3}\right| \cos \theta_{3} I_{Q s}$,

$\frac{\partial f_{6}}{\partial Y_{1}}=1, \frac{\partial f_{6}}{\partial Y_{17}}=-\cos \delta, \frac{\partial f_{6}}{\partial Y_{18}}=-\sin \delta$

$\frac{\partial f_{7}}{\partial Y_{19}}=\cos \theta_{3}\left|V_{3}\right| I_{D s}+\left|V_{3}\right| \sin \theta_{3} I_{Q s}, \frac{\partial f_{8}}{\partial Y_{4}}=1$,

$\frac{\partial f_{8}}{\partial Y_{17}}=\sin \delta, \frac{\partial f_{8}}{\partial Y_{18}}=\cos \delta, \frac{\partial f_{10}}{\partial Y_{7}}=1, \frac{\partial f_{10}}{\partial Y_{10}}=-1$,

$\frac{\partial f_{11}}{\partial Y_{13}}=-1, \frac{\partial f_{12}}{\partial Y_{6}}=\frac{1}{c V_{d c}}\left(I_{D r}\right), \frac{\partial f_{12}}{\partial Y_{3}}=\frac{1}{c V_{d c}}\left(I_{Q r}\right)$,

$\frac{\partial f_{12}}{\partial Y_{17}}=\frac{1}{c V_{d c}}\left(V_{D r}\right), \frac{\partial f_{12}}{\partial Y_{18}}=\frac{1}{c V_{d c}}\left(V_{Q r}\right)$,

$\frac{\partial f_{12}}{\partial Y_{9}}=\frac{1}{c V_{d c}}\left(-I_{D f}\right), \frac{\partial f_{12}}{\partial Y_{12}}=\frac{1}{c V_{d c}}\left(-I_{Q f}\right)$,

$\frac{\partial f_{12}}{\partial Y_{10}}=\frac{1}{c V_{d c}}\left(-V_{D f}\right), \frac{\partial f_{12}}{\partial Y_{13}}=\frac{1}{c V_{d c}}\left(-V_{Q f}\right)$,

$\frac{\partial f_{13}}{\partial Y_{14}}=\frac{1}{2 H_{t}}, \frac{\partial f_{14}}{\partial Y_{16}}=-\frac{1}{2 H_{g}}$,

\section{Matrix C}

$\frac{\partial g_{1}}{\partial X_{1}}=\cos \theta_{3}\left|V_{3}\right| K_{p 1}, \frac{\partial g_{1}}{\partial X_{2}}=\sin \theta_{3}\left|V_{3}\right| K_{p 1}$,

$\frac{\partial g_{1}}{\partial X_{5}}=-K_{i 1}, \frac{\partial g_{2}}{\partial X_{6}}=-K_{i 2}, \frac{\partial g_{3}}{\partial X_{1}}=-\left(\omega_{s}-\omega_{r}\right) L_{m} \sin \delta$

$\frac{\partial g_{3}}{\partial X_{2}}=-\left(\omega_{s}-\omega_{r}\right) L_{m} \cos \delta$

$\frac{\partial g_{3}}{\partial X_{14}}=L_{m}\left(\sin \delta I_{D r}-\cos \delta I_{Q r}+\sin \delta I_{D s}-\cos \delta I_{Q s}\right)$

$\frac{\partial g_{4}}{\partial X_{1}}=-\sin \theta_{3}\left|V_{3}\right| K_{p 3}, \frac{\partial g_{4}}{\partial X_{2}}=\cos \theta_{3}\left|V_{3}\right| K_{p 3}, \frac{\partial g_{4}}{\partial X_{7}}=-K_{i 3}$,

$\frac{\partial g_{5}}{\partial X_{8}}=-K_{i 4}, \frac{\partial g_{6}}{\partial X_{1}}=\left(\omega_{s}-\omega_{r}\right) L_{m} \cos \delta$,

$\frac{\partial g_{6}}{\partial X_{2}}=\left(\omega_{s}-\omega_{r}\right) L_{m} \sin \delta$

$\frac{\partial g_{6}}{\partial X_{14}}=-L_{m}\left(\cos \delta I_{D r}+\sin \delta I_{Q r}+\cos \delta I_{D s}+\sin \delta I_{Q s}\right)$

$\frac{\partial g_{7}}{\partial X_{12}}=K_{p 5}, \frac{\partial g_{7}}{\partial X_{9}}=-K_{i 5}, \frac{\partial g_{8}}{\partial X_{10}}=-K_{i 6}$,

$\frac{\partial g_{10}}{\partial X_{11}}=-K_{i 7}, \frac{\partial g_{14}}{\partial X_{13}}=C p V_{w}^{3} / \omega_{t}^{2}, \frac{\partial g_{15}}{\partial X_{13}}=R / V_{w}$

$c_{p}(\lambda, \beta)-c_{1} \underbrace{\left(c_{2}\left(\frac{1}{\lambda+0.008 \beta}-\frac{0.035}{\beta^{3}+1}\right)-c_{3} \beta-c_{4}\right)}_{q 1}$.

$\underbrace{e^{-c 5\left(\frac{1}{\lambda+0.008 \beta}-\frac{0.035}{\beta^{3}+1}\right)}}_{92}+C_{6} \lambda$,

$\frac{1}{\lambda_{i}}=\frac{1}{\lambda+0.008 \beta}-\frac{0.035}{\beta^{3}+1}$

$\frac{\partial g_{16}}{\partial X_{16}}=-c_{1}\left(c_{2}\left(\frac{-.08}{(\lambda+0.008 \beta)^{2}}+\frac{0.035^{*} 3^{*} \beta^{2}}{\left(\beta^{3}+1\right)^{2}}\right)-c_{3}\right) q_{2}$

$+c_{1} c_{5}\left(\frac{-.08}{(\lambda+0.008 \beta)^{2}}+\frac{0.035^{*} 3^{*} \beta^{2}}{\left(\beta^{3}+1\right)^{2}}\right) q_{1} q_{2}$

$\frac{\partial g_{17}}{\partial X_{1}}=\frac{L_{m}}{L_{r r}}, \frac{\partial g_{17}}{\partial X_{4}}=\frac{L_{m}}{\omega_{s}}, \frac{\partial g_{18}}{\partial X_{2}}=\frac{L_{m}}{L_{r r}}$,

$\frac{\partial g_{18}}{\partial X_{3}}=-\frac{L_{m}}{\omega_{s}}, \frac{\partial g_{19}}{\partial X_{1}}=-\frac{e_{D}^{\prime}}{\omega_{s}}, \frac{\partial g_{19}}{\partial X 2}=-\frac{e_{Q}^{\prime}}{\omega_{s}}$,

$\frac{\partial g_{19}}{\partial X_{3}}=-\frac{I_{D s}}{\omega_{s}}, \frac{\partial g_{19}}{\partial X_{4}}=-\frac{I_{Q s}}{\omega_{s}}$,

$\left|E^{\prime}\right|=\left(e_{D}^{\prime 2}+e_{Q}^{\prime 2}\right)^{0.5}, \delta_{e}=\tan ^{-1}\left(e_{Q}^{\prime} / e_{D}^{\prime}\right)$ 
$\frac{\partial g_{20}}{\partial X_{3}}=-2 e_{D}^{\prime}\left|E^{\prime}\right| 1 /\left|Z_{D F I G}\right| \cos \left(\alpha_{z D F I G}\right)+$

$e_{D}^{\prime}\left(e_{D}^{\prime 2}+e_{Q}^{\prime 2}\right)^{-0.5}\left|V_{3}\right| 1 /\left|Z_{D F I G}\right| \cos \left(\theta_{3}-\delta_{e}+\alpha_{Z D F I G}\right) \ldots$

$+\left|V_{3}\right|\left|E^{\prime}\right| 1 /\left|Z_{D F I G}\right| \sin \left(\delta_{e}-\theta_{3}+\alpha_{z D F I G}\right)^{*}\left(e_{Q}^{\prime} / e_{D}^{\prime 2}\right) /\left(1+e_{Q}^{\prime 2} / e_{D}^{\prime 2}\right)$

$\frac{\partial g_{20}}{\partial X_{4}}=2 e_{Q}^{\prime}\left|E^{\prime}\right| 1 /\left|Z_{D F I G}\right| \cos \left(\alpha_{z D F I G}\right)+$

$e_{Q}^{\prime}\left(e_{D}^{\prime 2}+e_{Q}^{\prime 2}\right)^{-0.5}\left|V_{3}\right| 1 /\left|Z_{D F I G}\right| \cos \left(\theta_{3}-\delta_{e}+\alpha_{Z D F I G}\right) \ldots$

$-\left|V_{3}\right|\left|E^{\prime}\right| 1 /\left|Z_{D F I G}\right| \sin \left(\delta_{e}-\theta_{3}+\alpha_{z D F / G}\right)^{*}\left(1 / e_{D}^{\prime}\right) /\left(1+e_{Q}^{\prime 2} / e_{D}^{\prime 2}\right)$

\section{Matrix D}

$\frac{\partial g_{1}}{\partial Y_{1}}=1, \frac{\partial g_{1}}{\partial Y_{19}}=-K_{p 1}\left(\left|V_{3}\right| \sin \theta_{3} I_{D s}+\left|V_{3}\right| \cos \theta_{3} I_{Q s}\right)$

$\frac{\partial g_{2}}{\partial Y_{1}}=-K_{p 2}, \frac{\partial g_{2}}{\partial Y_{2}}=1, \frac{\partial g_{2}}{\partial Y_{17}}=K_{p 2} \cos \delta$

$\frac{\partial g_{2}}{\partial Y_{18}}=-K_{p 2} \sin \delta, \frac{\partial g_{3}}{\partial Y_{2}}=-1, \frac{\partial g_{3}}{\partial Y_{3}}=1, \frac{\partial g_{4}}{\partial Y_{4}}=1$,

$\frac{\partial g_{3}}{\partial Y_{17}}=-\left(\omega_{s}-\omega_{r}\right) L_{m} \sin \delta, \frac{\partial g_{3}}{\partial Y_{18}}=\left(\omega_{s}-\omega_{r}\right) L_{m} \cos \delta$,

$\frac{\partial g_{4}}{\partial Y_{19}}=-K_{p 3}\left(\left|V_{3}\right| \sin \theta_{3} I_{Q s}+\left|V_{3}\right| \cos \theta_{3} I_{D s}\right), \frac{\partial g_{5}}{\partial Y_{4}}=-K_{p 4}$,

$\frac{\partial g_{5}}{\partial Y_{5}}=1, \frac{\partial g_{5}}{\partial Y_{17}}=K_{p 4} \sin \delta, \frac{\partial g_{5}}{\partial Y_{18}}=-K_{p 2} \cos \delta$

$\frac{\partial g_{6}}{\partial Y_{5}}=-1, \frac{\partial g_{6}}{\partial Y_{6}}=1, \frac{\partial g_{6}}{\partial Y_{17}}=\left(\omega_{s}-\omega_{r}\right) L_{m} \cos \delta$

$\frac{\partial g_{6}}{\partial Y_{18}}=\left(\omega_{s}-\omega_{r}\right) L_{m} \sin \delta, \frac{\partial g_{7}}{\partial Y_{8}}=1, \frac{\partial g_{8}}{\partial Y_{7}}=-K_{p 6}, \frac{\partial g_{8}}{\partial Y_{8}}=1$,

$\frac{\partial g_{9}}{\partial Y_{7}}=R_{f}, \frac{\partial g_{9}}{\partial Y_{8}}=1, \frac{\partial g_{10}}{\partial Y_{11}}=1, \frac{\partial g_{10}}{\partial Y_{13}}=K_{p 7}$

$\frac{\partial g_{9}}{\partial Y_{9}}=1, \frac{\partial g_{9}}{\partial Y_{19}}=\left(\left|V_{3}\right| \sin \theta_{3} \cos \delta+\left|V_{3}\right| \cos \theta_{3} \sin \delta\right)$,

$\frac{\partial g_{11}}{\partial Y_{7}}=-\omega_{s} L_{f}, \frac{\partial g_{11}}{\partial Y_{11}}=1, \frac{\partial g_{11}}{\partial Y_{12}}=1$,

$\frac{\partial g_{11}}{\partial Y_{19}}=\left(\left|V_{3}\right| \sin \theta_{3} \cos \delta-\left|V_{3}\right| \cos \theta_{3} \sin \delta\right)$, $\frac{\partial g_{12}}{\partial Y_{9}}=-1 /\left|Z_{\text {fiter }}\right|, \frac{\partial g_{12}}{\partial Y_{10}}=1$

$\frac{\partial g_{12}}{\partial Y_{19}}=-1 /\left|Z_{\text {filter }}\right| *\left|V_{3}\right| \sin \theta_{3}$,

$\frac{\partial g_{13}}{\partial Y_{13}}=1, \frac{\partial g_{13}}{\partial Y_{12}}=-1 /\left|Z_{\text {filter }}\right|$,

$\frac{\partial g_{13}}{\partial Y_{19}}=-1 /\left|Z_{\text {filter }}\right| *\left|V_{3}\right| \cos \theta_{3}$

$\frac{\partial g_{14}}{\partial Y_{14}}=1, \frac{\partial g_{14}}{\partial Y_{22}}=-V_{w}^{3} / \omega_{t}, \frac{\partial g_{15}}{\partial Y_{15}}=1, \frac{\partial g_{16}}{\partial Y_{22}}=1$,

$c_{p}(\lambda, \beta)-$

$c_{1} \underbrace{\left(c_{2}\left(\frac{1}{\lambda+0.008 \beta}-\frac{0.035}{\beta^{3}+1}\right)-c_{3} \beta-c_{4}\right)}_{91}$.

$\underbrace{e^{-c 5\left(\frac{1}{\lambda+0.008 \beta}-\frac{0.035}{\beta^{3}+1}\right)}}_{q 2}+c_{6} \lambda=0$,

$\frac{\partial g_{16}}{\partial Y_{15}}=c_{1} c_{2} \frac{1}{(\lambda+0.008 \beta)^{2}} q_{2}$

$+c_{5} \frac{1}{(\lambda+0.008 \beta)^{2}} q_{1} q_{2}$

$+c_{6}, \frac{\partial g_{17}}{\partial Y_{17}}=1, \frac{\partial g_{18}}{\partial Y_{18}}=1, \frac{\partial g_{19}}{\partial Y_{16}}=1$

$\left|V_{2}\right|^{2} 1 /\left|Z_{12}\right| \cos \left(\alpha_{12}\right)-\left|V_{3}\right|\left|V_{2}\right| 1 /\left|Z_{32}\right| \cos \left(\theta_{2}-\theta_{3}+\alpha_{32}\right)$

$+\left|V_{2}\right|^{2} 1 /\left|Z_{32}\right| \cos \left(\alpha_{32}\right)-\left|V_{1}\right|\left|V_{2}\right| 1 /\left|Z_{12}\right| \cos \left(\theta_{2}-\theta_{1}+\alpha_{12}\right)$

$+\left|V_{2}\right|^{2} 1 /\left|Z_{L}\right| \cos \left(\alpha_{L}\right)=0$

$\frac{\partial g_{20}}{\partial Y_{19}}=\left|V_{3}\right|\left|E^{\prime}\right| 1 /\left|Z_{D F I G}\right| \sin \left(\delta_{e}-\theta_{3}+\alpha_{z D F I G}\right)$

$+\left|V_{3}\right|\left|V_{2}\right| 1 /\left|Z_{32}\right| \sin \left(\theta_{3}-\theta_{2}+\alpha_{32}\right)$,

$\frac{\partial g_{20}}{\partial Y_{20}}=-\left|V_{3}\right| 1 /\left|Z_{32}\right| \cos \left(\theta_{3}-\theta_{2}+\alpha_{32}\right)$,

$\frac{\partial g_{20}}{\partial Y_{21}}=-\left|V_{3}\right|\left|V_{2}\right| 1 /\left|Z_{32}\right| \sin \left(\theta_{3}-\theta_{2}+\alpha_{32}\right)$,

$\frac{\partial g_{21}}{\partial Y_{19}}=-\left|V_{3}\right|\left|V_{2}\right| 1 /\left|Z_{32}\right| \sin \left(\theta_{2}-\theta_{3}+\alpha_{32}\right)$, 


$$
\begin{aligned}
& \frac{\partial g_{21}}{\partial Y 21}=\left|V_{3}\right|\left|V_{2}\right| 1 /\left|Z_{32}\right| \sin \left(\theta_{2}-\theta_{3}+\alpha_{32}\right) \\
& +\left|V_{1}\right|\left|V_{2}\right| 1 /\left|Z_{12}\right| \sin \left(\theta_{2}-\theta_{1}+\alpha_{12}\right) \\
& \frac{\partial g_{21}}{\partial Y 20}=2\left|V_{2}\right| 1 /\left|Z_{12}\right| \cos \left(\alpha_{12}\right)-\left|V_{3}\right| 1 /\left|Z_{32}\right| \cos \left(\theta_{2}-\theta_{3}+\alpha_{32}\right) \\
& +2\left|V_{2}\right| 1 /\left|Z_{32}\right| \cos \left(\alpha_{32}\right)-\left|V_{1}\right| 1 /\left|Z_{12}\right| \cos \left(\theta_{2}-\theta_{1}+\alpha_{12}\right) \\
& +2\left|V_{2}\right| 1 /\left|Z_{L}\right| \cos \left(\alpha_{L}\right) \\
& \frac{\partial g_{22}}{\partial Y_{19}}=\left|V_{3}\right|\left|V_{2}\right| 1 /\left|Z_{32}\right| \cos \left(\theta_{2}-\theta_{3}+\alpha_{32}\right) \\
& \frac{\partial g_{22}}{\partial Y 20}=2\left|V_{2}\right| 1 /\left|Z_{12}\right| \sin \left(\alpha_{12}\right)-\left|V_{3}\right| 1 /\left|Z_{32}\right| \sin \left(\theta_{2}-\theta_{3}+\alpha_{32}\right) \\
& +2\left|V_{2}\right| 1 /\left|Z_{32}\right| \sin \left(\alpha_{32}\right)-\left|V_{1}\right| 1 /\left|Z_{12}\right| \sin \left(\theta_{2}-\theta_{1}+\alpha_{12}\right) \\
& +2\left|V_{2}\right| 1 /\left|Z_{L}\right| \sin \left(\alpha_{L}\right), \frac{\partial g_{22}}{\partial Y 21}=-\left|V_{3}\right|\left|V_{2}\right| 1 /\left|Z_{32}\right| \cos \left(\theta_{2}-\theta_{3}+\alpha_{32}\right) \\
& -\left|V_{1}\right|\left|V_{2}\right| 1 /\left|Z_{12}\right| \cos \left(\theta_{2}-\theta_{1}+\alpha_{12}\right)
\end{aligned}
$$

